\title{
Mapping Connectivity in the Developing Brain
}

\author{
Emily L. Dennis ${ }^{1}$ and Paul M. Thompson ${ }^{1}$ \\ ${ }^{1}$ Imaging Genetics Center, Laboratory of Neuro Imaging, UCLA School of Medicine, Los Angeles, \\ CA, USA
}

\section{Abstract}

Recently, there has been a wealth of research into structural and functional brain connectivity, and how they change over development. While we are far from a complete understanding, these studies have yielded important insights into human brain development. There is an ever growing variety of methods for assessing connectivity, each with its own advantages. Here we review research on the development of structural and/or functional brain connectivity in both typically developing subjects and subjects with neurodevelopmental disorders. Space limitations preclude an exhaustive review of brain connectivity across all developmental disorders, so we review a representative selection of recent findings on brain connectivity in autism, Fragile X, 22q11.2 deletion syndrome, Williams syndrome, Turner syndrome, and ADHD. Major strides have been made in understanding the developmental trajectory of the human connectome, offering insight into characteristic features of brain development and biological processes involved in developmental brain disorders. We also discuss some common themes, including hemispheric specialization - or asymmetry - and sex differences. We conclude by discussing some promising future directions in connectomics, including the merger of imaging and genetics, and a deeper investigation of the relationships between structural and functional connectivity.

\section{Introduction}

After birth, the brain undergoes remarkable changes as it adapts and learns in a new environment. Over a century of neuroanatomical research has revealed how the brain changes structurally and functionally throughout development; the last thirty years have also seen the widespread use of brain imaging to probe functional activation and coherence, as well as other dynamic brain changes (reviewed by Casey et al., 2000). In addition to understanding these changes, it is equally important to understand how the underlying structural and functional connectivity of the mature adult brain are set up and refined in childhood and adolescence. With novel variants of MRI - such as diffusion imaging and resting state functional MRI - we now have the technology to image neural pathways reliably, and to assess relationships between the activity of different brain regions, opening up new avenues for research.

Diffusion weighted imaging (DWI) is a method that allows us to visualize the diffusion of water along axons and thus visualize axonal pathways. Originally based on the observation

(C) 2013 ISDN. Published by Elsevier Ltd. All rights reserved.

Please address correspondence to: Paul Thompson, PhD, Professor of Neurology \& Psychiatry, Imaging Genetics Center, Laboratory of Neuro Imaging, Department of Neurology, UCLA School of Medicine, 635 Charles Young Drive South, Suite 225, Los Angeles, CA 90095-7334, 310-206-2101, thompson@ loni.ucla.edu.

Publisher's Disclaimer: This is a PDF file of an unedited manuscript that has been accepted for publication. As a service to our customers we are providing this early version of the manuscript. The manuscript will undergo copyediting, typesetting, and review of the resulting proof before it is published in its final citable form. Please note that during the production process errors may be discovered which could affect the content, and all legal disclaimers that apply to the journal pertain. 
that the MRI signal is reduced when water is diffusing (Stejskal and Tanner, 1965), increasingly elaborate scanning methods were developed to assess the primary directions in which water is diffusing, at each location in the living brain. By modeling the directional diffusion of water as an ellipsoidal shape, or "tensor", at each voxel in the brain, diffusion tensor imaging (or DTI) may be used to follow the major fiber bundles of the white matter, and map smooth tracts running from one brain region to another. More recently, high angular resolution diffusion imaging (HARDI) has been developed, offering some advantages over DTI, as it can better map tracts in regions with crossing fibers (Jahanshad et al., 2011). Fractional anisotropy (FA), the degree to which water tends to diffuse in one concentrated direction (along the axon), is one of the most common measures used to assess axon integrity. Apparent diffusion coefficient (ADC) or mean diffusivity (MD) measures the overall magnitude of diffusion, regardless of the directions; low values for mean diffusivity indicate greater organization. As a general rule of thumb - which has many exceptions higher FA and lower MD tend to reflect more highly developed, more strongly myelinated tracts, with a higher axonal conduction speed. Many comparisons of diseased versus normal subjects find lower FA and higher MD in disease - this is also a general trend in the studies below, but is not universally the case.

The improved ability to disentangle fibers that mix and cross results from collecting more diffusion-weighted images at more angles, in conjunction with mathematical models that can resolve more than one dominant fiber direction in any given voxel (Cetingul et al., 2012a; Cetingul et al., 2012b). HARDI - essentially a more advanced form of diffusion imaging than DTI - differs from DTI in collecting diffusion data in more directions. It models the overall diffusion profile at each point in the brain using orientation distribution functions (ODFs) instead of tensors. ODFs estimate the probability of diffusion in each direction at each voxel, instead of assigning a single dominant diffusion direction to a given voxel (Tournier et al., 2004). For these reasons, HARDI is better at resolving crossing fibers (such as the corpus callosum and the long association fibers), a major issue for DTI (Tuch et al., 2002). These can then be separated and individually analyzed, giving a more accurate view of the brain's anatomical connections (Zhan et al., 2009a; Jin et al., 2012). As more directional scans are collected, longer scan times are needed, and this has provoked major efforts to speed up diffusion imaging (Zhan et al., 2011

Resting-state fMRI (rsfMRI) is a branch of research based on the idea that distant brain regions can be functionally coupled, whether or not they are structurally connected. RsfMRI data can be collected either in the presence or absence of a task. This coupling can be measured through the blood oxygenation level dependent (BOLD) time-courses of these distant regions. The phenomenon of synchronized low-frequency fluctuations $(\sim 0.01-0.1$ $\mathrm{Hz}$ ) in the BOLD signal of known functional networks was first found by Biswal et al. (1995), and led to the discovery of a number of temporally coherent networks (Damoiseaux et al., 2006; Fox et al., 2005) that have been replicated across individuals (Beckmann et al., 2005) and have high test-retest reliability, even in children (Thomason et al., 2011). There are three main methods to assess functional connectivity that we will consider here: seedbased, ICA (i.e., independent components analysis), and graph theory. In the seed-based approach, the researcher extracts the time course of a seed (region of interest) and then correlates that time course with the time courses of the rest of the voxels in the brain, to search for matches (Fox and Raichle, 2007). Brain regions with a high degree of positive correlation with the seed - i.e., those with a very similar time course - are thought to be functionally coupled. ICA (independent components analysis) is model-free, meaning that the researcher does not select a seed or ROI. Rather, the four-dimensional resting-state data can be decomposed into time courses and associated spatial maps, describing the temporal and spatial characteristics of the components making up the data (Beckmann et al., 2005). The same intrinsic connectivity networks (ICNs) can be seen with both seed-based and ICA 
approaches, and each method offers some advantages and disadvantages. Many possible roles have been attributed to ICNs, including memory functions, organization and coordination of neuronal activity, and priming the brain for coordinated activity (Fox and Raichle, 2007; Seeley et al., 2007). ICNs are altered in a wide range of psychiatric and developmental disorders, further motivating the need to establish how they develop in healthy individuals (Greicius, 2008), as well as metrics of normal brain function based on resting state data.

More pragmatically, there is also a major effort to understand how quickly information on brain connectivity can be collected, with techniques available today. When young children are assessed, scan times should be as short as possible without sacrificing important information, to avoid placing undue burden on the participants (Jahanshad et al., 2010; Zhan et al., 2008; Zhan et al., 2009b; Zhan et al., 2012a). Ongoing work is also determining how the chosen scanning protocols affect the maps of brain connectivity that are recovered (Zhan et al., 2012b). Clearly, the ability to pool and compare data collected worldwide on brain connectivity - including changes across development - depends on understanding how connectivity measures might depend on the scanners, protocols and methods used to extract maps of the brain's connections.

In this review, we will cover developmental changes in functional and structural connectivity in healthy, typically developing individuals (Table 1), along with a few illustrative examples of how connectivity may be disrupted in developmental disorders (Table 2). There is a much wider body of research covering how functional and structural connectivity are affected in individuals with neurological or psychiatric disorders, but those are beyond the scope of this review (Greicius, 2008; Lim and Helpern, 2002; Sexton et al., 2009; Seyffert and Silva, 2005; Uddin et al., 2010; please also see our previous review: Thomason \& Thompson, 2011). Here we consider a few developmental disorders that have been linked to alterations in structural and/or functional connectivity: autism, fragile $\mathrm{X}$ syndrome, 22q11.2 DS (deletion syndrome), Williams syndrome, ADHD (attention deficit hyperactivity disorder), and Turner syndrome. A few other recent reviews focus on the development of functional connectivity (Power et al., 2010; Uddin et al., 2010) or structural connectivity (Cascio et al., 2007; Schmithorst et al., 2010) either in typically developing or atypically developing individuals (Uddin et al., 2010; Walter et al., 2009). Here we consider how structural and functional connectivity develop in typically developing subjects and subjects with developmental disorders. Measures of structural and functional connectivity are related, and the patterns of coherent activity depend on the anatomical scaffolding where they take place. Establishing the developmental trajectory of these measures in typically developing individuals is critical to a thorough understanding of disorders that may affect them.

\section{Structural Brain Development in Healthy Subjects Developmental Studies using Structural MRI in Typically Developing Individuals}

Before we launch into our review of brain connectivity, first we give a brief background on brain structural development to put the subsequent sections in context. Changes in brain structure after birth are well established, from both post mortem and in vivo neuroimaging studies: the cerebrum increases in size into early adulthood (Giedd et al., 1999; Sowell et al., 2002; Gilmore et al., 2007; Knickmeyer et al., 2008), gray matter (GM) volume rises in infancy and then later decreases at different rates across the brain (Figure 1; Giedd et al., 1999; Sowell et al., 1999; Sowell et al., 2003; Gogtay et al., 2004; Gilmore et al., 2007), and white matter (WM) volume increases well beyond adolescence into middle age (Giedd et al., 1999; Sowell et al., 2002; Gilmore et al., 2007; Knickmeyer et al., 2008). Rates of growth for different brain regions have even been mapped in neonates and infants, based on 
anatomical MRI (Gilmore et al., 2007; Knickmeyer et al., 2008). Building on early work by Gogtay et al. (2004), Shaw et al. (2008) found that cortical thickness follows different trajectories depending on the brain region. Intriguingly, the complexity of the growth trajectory of the brain region (linear vs. quadratic vs. cubic) seemed to correspond to the complexity of the laminar architecture. As a general principle, many of the last cortical areas to mature - those with the most protracted period of development - are typically those that are phylogenetically most recent and responsible for higher order cognitive processes, such as the frontal and prefrontal cortices (Gogtay et al., 2004). A great deal of work in developmental neuroscience has focused on studying the relatively late maturation and remodeling of the frontal lobe gray matter, which shows detectable changes on MRI well into late adolescence, long after the maturation of primary sensorimotor and visual cortices. It has been argued that the natural process of gray matter reduction in adolescence is abnormally intensified or derailed in some forms of psychosis, including schizophrenia. "Time-lapse maps" of abnormal cortical development show a dynamically spreading wave of adolescent gray matter loss in schizophrenia (Thompson et al., 2001; Vidal et al., 2006), which may even be partially opposed by some antipsychotics (Thompson et al., 2009). As the cellular basis of these cortical changes has remained enigmatic and hotly debated, there is renewed interest in whether new methods to probe brain connectivity will reveal more about normal changes in the frontal circuitry - whether connections are eliminated or "pruned", and to what extent aberrant myelination is implicated.

Zielinski et al. (2010) examined the structural covariance of regions known to be "seeds" for functional connectivity networks and found different trajectories for different networks. Some continuously grew in extent, while others peaked in adolescence and were then pruned. On a much smaller scale, Huttenlocher found that the number and density of synapses peaks within the first few years after birth, then steadily declines over the lifespan (Huttenlocher, 1990). The age at which synaptic number and density peaks differs for different brain regions (Huttenlocher and Dabholkar, 1997).

\section{Developmental Studies using Diffusion Weighted Imaging in Typically Developing Individuals}

Changes in structural brain connectivity (i.e., anatomical connections) have been mapped using diffusion tensor imaging (DTI), and more recently with high angular resolution diffusion imaging (HARDI). Both HARDI and DTI allow us to non-invasively visualize axonal pathways in vivo by modeling the diffusion of water along axons. From the set of diffusion tensors at each point in the brain, we can determine vectors along which the diffusion is greatest and line them up to create smooth tracts (Figure 2). A vast range of methods are available to perform fiber tracking - also known as tractography; the methods vary in terms of whether any manual interaction is needed, and whether they extract a specific tract in the brain (such as the arcuate fasciculus, which is involved in language) or whether they extract all the fibers in the brain at once. Whole-brain tractography can extract all the fibers in the brain at once. The vast number of resulting curves can be clustered or grouped into bundles that an anatomist would recognize, prior to further analysis or crosssubject comparison. The integrity and geometry of the tracts can also be measured.

Morriss et al. (1999) scanned 30 subjects between 1 day old and 17 years old with DTI, and found a decrease in ADC across a number of WM areas with age. In cellular terms, the growth of myelin sheaths tends to restrict water diffusion, and the overall amount of diffusion (the ADC) tends to fall as the brain develops. In a retrospective analysis, Mukherjee et al. (2001) examined DTI data from 153 subjects between 1 day old and 11 years old and found increases in apparent anisotropy (AA; a measure similar to FA) in the corpus callosum (CC), basal ganglia and thalamus. Again, this is in line with a general pattern where higher FA values reflect more directionally constrained diffusion, which 
increases as children grow older, largely because of myelin sheaths hindering water diffusion across axons. Zhai et al. (2003) examined healthy adults and neonates with DTI and found higher ADC and lower FA in the CC, internal capsule (IC), and WM of the frontal and occipital cortex of neonates compared to adults, as expected. In another study of neonates, Gilmore et al. (2004) saw an increase in FA in the splenium of the CC with age. Gao et al. (2009a) scanned 60 subjects between 3 weeks and 2 years old and found that FA increased between 3 weeks and 1 year while axial and radial diffusivity decreased. Between 1 and 2 years old, however, only radial diffusivity showed a significant age effect, which makes sense as the primary barrier to diffusion, myelin, is hindering diffusion orthogonal to the axon. These were averaged over ROIs (regions of interest) across the CC, internal capsule, corticospinal tract, optic radiations, frontal peripheral and posterior peripheral WM.

Covering a wider age range, Ben Bashat et al. (2005) scanned 36 subjects between 4 months and 23 years old with DTI and also found FA increasing in the CC, IC, and subcortical WM, leveling off in early adulthood. Similarly, Taki et al. (2012) examined the developmental trajectories of FA in 30 WM ROIs in 246 subjects aged 6-18 and found that FA increased with age across all ROIs. Covering the same age range, Barnea-Goraly et al. (2005) examined age-related effects on FA on a voxel-by-voxel basis in 34 subjects between 6-19 years old. FA increased with age in prefrontal regions as well as a number of subcortical regions. This is the general trend across adolescence (review by Schmithorst \& Yuan, 2010). Two studies examining the corpus callosum across almost the entire lifespan found that both $\mathrm{CC}$ volume and FA increased from childhood into adulthood, then declined in the elderly (McLaughlin et al., 2007; Hasan et al., 2009a). Just like the rest of the brain, different regions of the CC follow different developmental trajectories (Thompson et al., 1999; Thompson et al., 2000). Using a protocol with higher angular resolution, Schneider et al. (2004) examined WM regions of interest, including several across the corpus callosum, and found an exponential increase in FA between birth and age 12, leveling off around age 2 . In contrast, they found that the FA of deep WM areas continued to increase throughout the age range of their participants, suggesting continuing maturation in these areas. Also using higher angular resolution, Giorgio et al. (2008) compared 42 adolescents to 20 young adults and found age-related increases in FA in the body of the corpus callosum and the right superior corona radiata.

In one of the largest DTI studies to date, Kochunov et al. (2010) examined the trajectory of FA across subjects aged 11-90, finding that FA, when averaged across nine major WM tracts, peaked around 32 years of age. The 'age at peak' for the FA of the nine tracts they studied varied widely, from 23 years for the sagittal stratum, which connects subcortical, temporal, and occipital regions, to 39 for the cingulum, connecting the cingulate gyrus and the entorhinal cortex. The only tract showing no significant age trends was the cortico-spinal tract (Kochunov et al., 2010); this fundamental tract for sensation and primary motor function develops so early that it is fully mature before the age range studied. In a similarly large study, Chiang et al. (2011) found that FA increased by as much as $10 \%$ between adolescence and adulthood. They also examined how the heritability of FA changes with age (i.e., how much of the observed variation in a population is due to genetic factors). Roughly twice as much of the variance in FA was explained by genetic factors in adolescents as was explained by genetic factors in adults (Chiang et al., 2011). Environmental factors (such as education and diet) may play an ever-increasing role in shaping tract development as we age (Jahanshad et al., 2013a).

Asato et al. (2010) also examined this period of development, scanning 114 subjects between $8-28$ years with DTI. Instead of FA, however, they looked at radial diffusivity (RD), a measure of the degree of restriction due to membranes, which is thought to be more closely related to demyelination than other DTI measures (Asato et al., 2010). The last tracts 
to reach maturity were those responsible for executive control of behavior and interhemispheric connectivity.

Jahanshad et al. (2012) examined this question from a somewhat different angle. They collected DTI data from 615 subjects - all twins and their siblings - between 20-30 years old, with blood samples also collected at an early age. There is great interest in knowing whether fiber maturation proceeds in a way that is largely genetically determined, and how much it depends on more readily modifiable factors - environmental factors such as nutrition, education, and other experiences. Specifically, Jahanshad et al. studied how iron levels in the body affect fiber integrity, and they looked at the relationship between serum transferrin (which regulates iron transport) collected at an earlier age, and two genetic variants that are associated with transferrin levels, and fiber integrity in early adulthood. They found that higher serum transferrin levels in adolescence were associated with lower FA in the cingulum, superior longitudinal fasciculus, and external capsule. High transferrin levels tend to reflect low iron levels - when iron stores are low, the liver produces more transferrin to mobilize what little iron there is, and transport it around the body. In other words, children with poorer iron levels tended to have lower FA, which typically reflects either poorer fiber integrity, or a developmental delay (Thompson \& Jahanshad, 2012). Iron is one of many constituents of myelin, and this work suggests the value of studying how dietary factors contribute to the developing connections in the brain.

\section{Developmental Studies using Structural Graph Theory Analyses in Typically Developing Individuals}

Graph theory is a branch of mathematics developed to describe and analyze graphs and networks, and it has recently been applied very effectively to brain networks, among many other kinds of networks (such as the internet, social networks, etc.; Sporns et al., 2004). The brain may be modeled as a collection of nodes (brain regions) and edges (the connections or correlations between them). The network structure and topology is then quantified through a number of standard parameters (Figure 3). Standard toolboxes, such as the "Brain Connectivity Toolbox" have made it easier to compute measures of network organization from brain images. We are beginning to develop a coherent picture of what some of the organizational measures may mean, in terms of other developmental and behavioral changes that we are more familiar with.

As network analysis is now a popular way to understand developing brain connectivity, some review of the terminology is worthwhile. Characteristic path length is an average measure of the path length in a network. This can be a little confusing, as it does not refer to the physical length of the axon connecting different regions - it is a purely topological measure, describing how many "hops" or jumps among nodes in the network are needed to get from one node to another. In other words, it measures how easy it is to move from one node in a network to any of the others, regardless of the physical length of the axons, but only considering what is connected. Another measure, lambda, is the CPL measure, but normalized relative to what its value would be in randomly created networks of the same size and complexity. Clustering of nodes in a network can be assessed, as well. The mean clustering coefficient is a measure of how many neighbors of a given node are also connected to each other. Clearly, most real-world networks have "hubs" - nodes that offer connections to a large number of other nodes that are not directly connected. In biological networks (and other networks where connections have some "cost"), a network with "hubs" tends to be more efficient than a totally connected network where everything is directly connected to everything else. This can be readily understood in terms of airline connections, where airline "hubs" are used to supply many remote cities with indirect connections to other cities. In much the same way as synapses are pruned if they are not active, one can 
imagine a model where the most active connections are maintained, while others die off, leading to a more clearly defined network with hubs and clusters.

Another network measure, Gamma, is MCC normalized to what its value would be in artificially created random networks, with the same numbers of nodes and connections. Global efficiency is the inverse of CPL - networks with a lower CPL are more efficient. Another popular concept - "small-worldness"- represents the balance between network differentiation and integration. Modularity is the degree to which a system may be subdivided into smaller networks. Degree is the number of nodes to which a given node is connected; strength is the degree in a weighted (instead of binarized) network. Regional efficiency is efficiency calculated on nodal neighborhoods. Graph theory can be applied to structural or functional networks (Rubinov and Sporns, 2010).

There are still relatively few studies examining how graph theory metrics of structural brain connectivity change with development. Gong et al. (2009) examined the standard network measures calculated from connectivity probability matrices generated from diffusion images in 95 subjects between ages 19-85. Overall connectivity and local efficiency decreased with age, and there was a shift in regional efficiency from some brain regions to others (Figure 4). Hagmann et al. (2010) studied changes in connection density matrices from the diffusion images of 30 subjects aged 18 months to 18 years old. They examined these matrices with two parcellations with different numbers of nodes, and found increases in node strength and global efficiency as well as decreases in clustering coefficient. Fan et al. (2011) studied these measures longitudinally in very young subjects, between 1 month and 2 years old. They found increases in network efficiency and modularity with age.

Our group has investigated these questions as well, generating fiber density matrices from HARDI data in 439 subjects aged 12-30 (Dennis et al., accepted). Path length, mean clustering coefficient, gamma (normalized clustering), small-worldness, and modularity all decreased with age, suggesting that this period of development is marked by an increase in network integration. Interestingly, the left and right intrahemispheric networks, when analyzed separately, showed opposing age trends, with a number of parameters increasing with age in the left hemisphere while they decreased in the right. If this is corroborated in future studies, it could point to different developmental processes occurring in each hemisphere, perhaps due to the known structural asymmetry of the brain. We also found age effects in the fiber density matrices, with more connections decreasing in fiber density than increasing. In these analyses, for a connection between two regions of interest, the fiber density is defined as the proportion of the total number of recovered fibers in the brain that pass between those two regions. However, these increases and decreases were not distributed evenly around the brain, consistent with prior research pointing to different developmental trajectories for various brain regions (Figure 5).

\section{Functional Brain Development in Healthy Subjects}

In functional connectivity analyses, the activity of several different brain regions is assessed, and the relationship between them is studied and modeled. This may be done in several different ways, depending on whether the researcher is interested in the correlations in the time courses of activation between a given pair (or all pairs) of brain regions. The statistical coherence of activity measured from different parts of the brain can also be studied, including more complex measures such as mutual information. The coordination of distant regions during rest is thought to be involved in coordinating and organizing neuronal activity (Fox and Raichle, 2007). 


\section{Developmental Studies using Seed-Based or ICA rsfMRI Approaches in Typically Developing Individuals}

Studies of functional connectivity using resting-state functional MRI have also yielded substantial data on typical brain changes during development. Supekar et al. (2010) examined developmental changes in the structural and functional connectivity of the nodes of the "default mode network" (DMN). The DMN is a generally thought to include the posterior cingulate cortex (PCC), medial prefrontal cortex (mPFC), inferior parietal lobules, lateral temporal cortices, and hippocampal formation (Buckner et al., 2008; Raichle et al., 2001). These regions tend to be more active during rest than during a task, hence the name 'default mode', or 'task negative' network (Fox et al., 2005). Supekar et al. (2010) also found that the fiber density and FA of the connection between the PCC and the mPFC was greater in young adults than in children (Figure 6).

Using the seed-based approach, Redcay et al. (2007) examined functional connectivity in 13 subjects between 30-50 months old with seeds from tasks completed in the same scan session. They detected functional connectivity between the auditory system and the prefrontal cortex (PFC) but not between the visual system and PFC. Looking at a similar age group, Lin et al. (2008) examined the visual and sensorimotor networks of 38 subjects. Both the strength of the connectivity, and the percentage of the brain volume participating in the networks, increased with age. In a study of 12 premature infants between 24-27 weeks gestational age, Fransson et al. (2007) used ICA and were able to identify networks in the visual, auditory, motor and somatosensory, and prefrontal cortices, as well as one including areas of the parietal cortex and cerebellum. Networks were largely characterized by shortrange connections, and they did not detect a DMN. Liu et al. (2008) also used ICA to examine connectivity in very young subjects (11 sub 11-14 months) while asleep, and found a midline parietal network and a sensorimotor network (that separated into two lateralized networks in most subjects), suggesting greater intrahemispheric than interhemispheric connectivity. Similarly, Gao et al. (2009) scanned 71 subjects ranging from neonates to 2 years old and used ICA to detect the DMN. They found a primitive DMN in neonates that grew through age 2 to include some of the same regions found in the adult DMN. They also identified some additional regions not typically seen in the adult DMN. The PCC and MPFC were the two adult DMN regions that were present throughout all three developing groups as well.

Examining later stages of development, Fair et al. (2008) scanned 210 subjects between 731 years old and compared connectivity within the DMN. Children had sparser connections between DMN seeds than did adults (Figure 7). Kelly et al. (2009) looked at ICNs generated by using 5 seeds for 40 subjects in the cingulate cortex and found that children had more diffuse patterns of connectivity in voxels proximal to the seed, while over adolescence and into adulthood there were more focal patterns of local connectivity. Adults also had a greater number of long-range connections than did children. This was most apparent in networks that included areas responsible for conflict monitoring, emotion regulation, and mentalizing. Providing strong support for using rsfMRI measures as biomarkers, Dosenbach et al. (2010) were able to classify individuals as either children (7-11 y) or adults (24-30 y) with $91 \%$ accuracy using multivariate pattern analysis and an SVM (support vector machine) algorithm. They scanned 238 subjects and generated time courses for 160 ROIs for use in their algorithm. Impressively, they were able to replicate these results with a different data set.

Using ICA, Thomason et al. (2008) studied the DMN in 16 subjects aged 9-12 years to verify that the regions of the DMN in children are indeed those that deactivate during cognitive tasks. They also found evidence of greater integration between the DMN and sensory regions in children. Stevens et al. (2009) scanned 100 subjects between 12-30 years 
and examined the relationships between networks using ICA and 'Granger causality' - a statistical hypothesis test for deciding when one time-series is useful for forecasting another. Where there were age effects, they were decreases in connection strength between networks with age, reflecting a trend towards differentiated networks. Specifically, they found decreases in the influence that some networks had on the DMN. Supekar et al. (2010) used ICA to investigate age-related effects on the DMN in 45 subjects in two age cohorts. The DMN in children had weaker connectivity and included a smaller portion of the mPFC. This resulted in lower functional connectivity between the $\mathrm{MPFC}$ and the PCC, a central node of the DMN. Using seeds motivated by ICA analysis, Thomason et al. (2011) detailed the ICNs of 65 children/adolescents between 9-15 years old (Figure 8). 21 of the 65 subjects were scanned a second or third time, allowing for longitudinal analyses. They found that the within-session Kendall's $W$ concordance ranged between $0.71-0.78$ across the whole brain, while between sessions it was 0.60-0.65, supporting the notion that rsfMRI can be reliably assessed in children.

\section{Developmental Studies using Functional Graph Theory Analyses in Typically Developing Individuals}

Graph theory may also be applied to study functional connectivity, using any measure of functional coupling between nodes that can be expressed in a connectivity matrix correlation, coherence, or mutual information (Bullmore and Sporns, 2009). So far, developmental studies of functional connectivity with graph theory are few. Fair et al. (2007) examined 210 subjects in three different age cohorts between 7-31 years old and extracted the time courses for 39 ROIs. In graph analyses of the connectivity matrices, adults had both greater integration within networks and greater segregation between networks than did children. Both of these processes are important for establishing mature networks that can support specific functions, while also efficiently participating in the brain network as a whole. In a larger sample including the same subjects, Fair et al. (2009) found that the pattern of functional connectivity matures from being more anatomically based to being more functionally based. Initially, functional networks are organized by lobe, but across development connections within the lobe weaken as networks segregate. Concurrently, in childhood, networks such as the DMN are initially segregated, and they consist of many spatially distributed regions. Across development, however, functional networks such as the DMN become more cohesive (Figure 9). In a similar age group, Supekar et al. (2009) also examined ICNs and whole brain connectivity using graph theory in 45 subjects in two age groups (7-9 years and 19-22 years). Results did depend on the frequency range examined, so the authors chose to focus on one. Children had lower levels of hierarchical organization than adults, as well as stronger subcortical-cortical connectivity and weaker cortico-cortical connectivity. Additionally, the authors saw a shift from stronger short-range connections in children to stronger long-range connections in adults, consistent with many other studies on this topic.

\section{Structural and Functional Connectivity in Atypical Brain Development}

\section{Autism}

Autism is a prevalent neurodevelopmental disorder marked by deficits in communication and social interaction, and by repetitive behavior. It has some genetic basis, but the large and increasing number of genes linked to autism indicates a rather complicated mechanism (Szatmari et al., 2007). Diffusion imaging studies show widespread disruption of white matter tracts, especially between regions implicated in social behavior (Barnea-Goraly et al., 2004; Barnea-Goraly et al., 2010; Shukla et al., 2010). Bashat et al. (2007) found evidence to support abnormally accelerated maturation of white matter in children with autism, 
consistent with earlier morphometric work that showed accelerated brain growth in infancy, for at least one subgroup of children with autism.

A number of studies have examined ICNs (intrinsic connectivity networks) in individuals with autism. They have largely found evidence for reduced network integration in autism, especially in areas important for social cognition (Cherkassky et al., 2006; Just et al., 2007; Kennedy et al., 2008; Weng et al., 2010), but some found results in the opposite direction (Monk et al., 2009; Noonan et al., 2009). Additionally, some have reported reduced segregation between networks, suggesting that both within- and between-network dynamics may be affected (Rudie et al., 2012b).

\section{Fragile-X}

A related syndrome, fragile $\mathrm{X}$, accounts for around 5\% of autism cases, making it the most common known single-gene cause of autism (Budimirovic et al., 2011). Haas et al. (2009) found an increased density in the fibers of the left ventral fronto-striatal pathway in young boys with fragile X. Barnea-Goraly et al. (2003) scanned girls with fragile $\mathrm{X}$ and found that they had lower FA in fronto-striatal pathways - usually a sign of poorer myelination relative to healthy controls. To date, we know of no studies examining the development of functional connectivity in individuals with fragile $\mathrm{X}$.

\section{2q11.2 Deletion Syndrome}

22 q11.2 deletion syndrome (22q DS) is a developmental syndrome resulting from a deletion of genetic material on chromosome 22 , and is associated with cognitive deficits, differences in appearance, and other physiological changes. DTI studies in people with 22q DS report a number of abnormalities, including reduced interhemispheric FA, increased FA in frontal and parietal regions, and reduced FA in some anterior-posterior projecting tracts (Simon et al., 2005; Simon et al., 2008; Sundram et al., 2010; Villalon et al., 2013).

Only one group so far has investigated resting state connectivity in 22q DS. Debbané et al. (2012) used ICA to compare the ICNs of individuals with 22q DS, finding both increased and decreased connectivity in individuals with 22q DS, depending on the brain regions assessed. Individuals with 22q DS had decreased connectivity in the visual network. They had greater connectivity in the sensorimotor network and visuospatial processing network. Additionally, they had altered connectivity in the default mode network, with decreased connectivity between a number of midline frontal regions and the precuneus, and increased connectivity between more lateral frontal regions and the inferior parietal lobule.

\section{Williams Syndrome}

Williams syndrome is another neurodevelopmental disorder caused by a deletion, this time on chromosome 7q11.23. Hallmarks of Williams syndrome (WS) include hypersociability and decreased social inhibition. Structural connectivity studies of WS have found increased FA in the right superior longitudinal fasciculus, an increase that was associated with visuospatial deficits (Hoeft et al., 2007). Similarly, Jabbi et al. (2012) linked decreases in uncinate integrity to the severity of the WS personality profile. Researchers have also found increased fiber volume, density, and FA in the fusiform gyrus, an area important for facial processing and thus social interaction (Haas et al., 2011). Still others have found scattered increases and decreases in FA across tracts connecting regions implicated in the syndrome (Arlinghaus et al., 2011). This very complex picture is in line with morphometric work on WS, which tends to show a pattern of relative excesses and deficits in cortical gray matter thickness, and even differences in the gyral complexity of the cortical surface (Thompson et al., 2005). Earlier studies with MRI found imbalances in the distribution of white matter in the WS brain (Chiang et al., 2007), making tract tracing studies of particular interest in these 
regions. In cases where the fissuration pattern of the cortex is very different from that seen in typically developing children, one must be somewhat cautious in applying the standard cortical parcellation schemes derived from normal subjects, to define the network nodes in connectivity studies. Clearly, tractography and connectivity analysis will shed considerable light on the unusual sulcal, gyral and corpus callosum abnormalities that have long been known to be characteristic of WS (Eckert et al., 2006; Gaser et al., 2006; Luders et al., 2007). As yet, we do not know of any studies examining the development of functional connectivity in individuals with Williams syndrome.

\section{Turner Syndrome}

Turner syndrome results from partial or complete absence of one $\mathrm{X}$ chromosome in females, and is associated with a number of physical and physiological abnormalities. Molko et al. (2004) was the first to examine white matter integrity with DTI in girls with Turner syndrome (TS), finding disruptions in anterior-posterior running temporal tracts. Holzapfel et al. (2006) found lower FA in the bilateral internal capsule as well as in the left parietooccipital region, extending along the superior longitudinal fasciculus. Yamagata et al. (2012) found widespread reductions in FA in girls with TS in a number of tracts connecting regions implicated in the cognitive deficits characteristic of TS. Turner syndrome (TS) is marked by widespread deficits in white matter pathways, especially in anterior-posterior tracts, so it is not surprising that functional connectivity is altered as well. Kesler et al. (2007) report unpublished data in which they found negative correlations between the time series of frontal and parietal regions in girls with TS, while controls had positive correlations between those regions' time series. Bray et al. (2011) found decreased functional connectivity to a seed in the right intraparietal sulcus (rIPS), an area shown to differ structurally in TS, in girls with TS during a working memory task. Later, Bray et al. (2012) found alterations in the functional connectivity of the posterior parietal cortex of girls with TS.

\section{Attention Deficit/Hyperactivity Disorder}

As one of the most prevalent developmental disorders (Froehlich et al., 2007), ADHD (attention-deficit/hyperactivity disorder) is also one of the most commonly studied. ADHD is disproportionately diagnosed in boys (Anderson et al., 1987). It is a heterogeneous disorder, with a strong familial factor (Biederman, 2005). As such, we will only summarize a sample of the work on altered connectivity in ADHD. Some studies report lower FA in children with ADHD (Ashtari et al., 2005; Hamilton et al., 2008; Pavuluri et al., 2009), which is typically interpreted as evidence of disruption of the motor and attentional circuits. Others find higher FA in children with ADHD (Li et al., 2011; Silk et al., 2009), perhaps due to decreased neuronal branching. Additionally, $\mathrm{Li}$ et al. (2011) were able to correlate FA in the right frontal region with scores on the Stroop test, a test of inhibition and interference control. A line of interesting work will be to relate these patterns of aberrant connectivity to the last decade of work on structural brain abnormalities in ADHD, including, for example, the reported anomalies in callosal thickness (Luders et al., 2008) and cortical gray matter thickness (Sowell et al., 2003).

A number of studies have examined functional connectivity in ADHD (attention-deficit/ hyperactivity disorder), with some conflicting results. Part of this may lie in the heterogeneity of ADHD (Wåhlstedt et al., 2009). Cao et al. (2006) found increased temporal synchrony between a number of visual regions and the parahippocampal gyrus, while they found decreased synchrony between a number of frontal regions, the caudate, and precuneus. Examining the DMN, Castellanos et al. (2008) found decreased connectivity between the anterior cingulate (ACC) and the precuneus/posterior cingulate. Tian et al. (2006) also studied the connectivity of the ACC and found increased connectivity with the thalamus, cerebellum, insula, and pons. Taking a graph theoretical approach, Wang et al. 
(2009) found increased local efficiency and decreased global efficiency in children with ADHD, suggesting a disruption in the balance of small-world characteristics. There were also differences in nodal efficiency in prefrontal, temporal, and occipital regions implicated in previous studies.

\section{Common Themes}

A number of themes have been common in investigations of structural and functional connectivity networks. Brain asymmetry has interested researchers for years (Hellige, 1993; Toga and Thompson, 2003), and sex differences in the brain are a controversial topic that has generated much research that is occasionally conflicting, partly due to the nonlinear scaling of brain structures as brain size increases (Gur et al., 1999; Kimura, 2000, Sowell et al., 2006; Brun et al., 2009; Lueders et al., 2013). Even sex differences in the degree of brain asymmetry have been investigated in some depth (McGlone, 1978; McGlone, 1980;

Shaywitz et al., 1995; Toga and Thompson, 2003). Examining how these each change over development is an important part of understanding development and the factors that give rise to asymmetry or sex differences in the brain. Because asymmetry and sex differences in the brain are broad enough topics to be a review or book in themselves (Dimond and Beaumont, 1974; Hellige, 1993; Kimura, 2000), here we will limit our review to the asymmetry and sex difference findings in studies we have already discussed here.

\section{Asymmetry}

Giedd et al. (1996) detailed the developmental changes in regional tissue volumes across different lobes, noted a right greater than left asymmetry in the temporal lobe, amygdala, and hippocampus. They did not see any changes in this asymmetry with age, however. In their study of 20 neonates, Gilmore et al. (2004) found a significant asymmetry in the lateral ventricles with the left being greater than the right; this asymmetry involves the left occipital horn projecting further back in the brain than its counterpart on the right, and it is almost universally found in studies of brain morphometry, regardless of the age and diagnosis of the subjects. In a more in-depth study, Gilmore et al. (2007) assessed 74 infants between 38 and 48 weeks gestational age. The left hemisphere was larger in volume than the right, which is opposite to typical findings in older children and adults (even the literature on this overall asymmetry in hemispheric volume is somewhat mixed, see Toga and Thompson, 1997). This left-greater-than-right asymmetry was detected in the GM, WM, subcortical GM, and lateral ventricles. Examining diffusion-weighted images in 108 subjects aged 7-68, Hasan et al. (2009b) found a leftward asymmetry in the FA of the uncinate fasciculus. They found this to be due to a leftward asymmetry in the axial diffusivity and a lack of asymmetry in the radial diffusivity. Jahanshad et al. (2010) even found that asymmetry in the FA of major WM tracts had a genetic basis. Our group found an unexpected asymmetry in the developmental trends for graph theoretical measures of structural connectivity, with measures increasing with age in the left hemisphere and decreasing in the right hemisphere (Dennis et al., submitted). Ongoing studies are revealing complex differences in the wiring patterns of each brain hemisphere, some of them in language-related regions, in line with the well-known morphometric asymmetries of the planum temporale and perisylvian cortices (Daianu et al., 2012).

\section{Sex Differences}

Sex differences in the brain are a controversial topic, and research in this area can be conflicting, but there are sex differences in vulnerability to various neuropsychiatric disorders or recovery from brain injury (Turkheimer \& Farace, 1992). As such, investigating sex differences in the brain will hopefully shed light on key health issues and their determinants. Giedd et al. (1996) found greater overall cerebral volumes in males, even 
when controlling for height and weight. In a later study, Giedd et al. (1999) similarly found greater overall GM volumes in males, as well as sex differences in the age at which cortical GM volume peaked. Sowell et al. (2002) found a few structures for which females had greater relative volume, including the temporal cortex, thalamus, caudate, and basomesial diencephalic structures. Finding differences even in neonates, Gilmore et al. (2004) recorded larger lateral ventricular volume in females than males. Later, Gilmore et al. (2007) found significantly greater intracranial volume (ICV) in males than females, even controlling for body weight.

Turning to structural connectivity, Gong et al. (2009) found a number of graph theoretical measures of structural brain connectivity that showed sex differences. Regional efficiency differed between sexes across many nodes, with some showing greater efficiency in females and some in males. Men had greater efficiency in a few frontal nodes while females had greater efficiency in a number of temporal, parietal, and occipital nodes. Dennis et al. (2013) found sex differences in a number of global and nodal measures in graph theoretical measures of structural brain connectivity. We found greater clustering in females, who may have more segregated networks. We also found differences in the regional efficiency and degree (number of connections) in a few nodes. As the brain's components do not scale proprtionately to the overall size of the brain, some care is needed when interpreting sex differences: some studies comparing short men with taller women find the sex effects in the opposite direction, suggesting that body size may account for some reported sex differences (Luders et al., 2013).

In functional connectivity, Schmithorst \& Holland (2007) found a sex difference in correlations between intelligence and functional connectivity, with males and females showing intelligence scores correlated with functional connectivity of different regions. They also found an age by sex interaction in this effect. Kilpatrick et al. (2006) found that the functional connectivity of the amygdala demonstrated a sex effect, with males showing more expansive connectivity of the right amygdala and females showing more expansive connectivity of the left amygdala. Examining functional connectivity using graph theoretical methods, Wang et al. (2008) found a sex effect on nodal efficiency. Females had greater nodal efficiency in frontal and temporal regions, but males had greater efficiency in limbic and paralimbic regions. A review by Gong et al. (2011) provides greater detail on sex differences found across these various neuroimaging methods.

\section{Future Directions}

Connectivity is a popular research topic now and has been for a few years. This growing popularity has led to major advances in the methods we use to assess connectivity. No doubt these improvements will continue as we search the human connectome in more depth and in new ways (see Toga and Thompson, 2013 and Engel et al., 2013, for up to date reviews). Another topic that we expect to attract more attention is the relationship between structural and functional connectivity. Some studies are beginning to examine changes in functionstructure relationships during development, and there are still many intriguing questions on how the two interact.

\section{Imaging Genetics}

Imaging genetics (reviewed in Glahn et al., 2007; Thompson et al., 2010) is another topic that is gaining momentum and has already amassed a sizeable body of research. With the advent of better genomic methods and cooperative groups that can collect larger datasets, genetic analysis of variations in brain images can be pursued to discover specific genetic variants that affect brain integrity and connectivity (Jahanshad et al., 2013b). Several autism risk genes, for example, may be associated with consistent differences in brain "wiring", in 
both anatomical and functional connectivity analyses (Dennis et al., 2011; Rudie et al., 2012a). Also, new methods have recently been developed to screen connectivity maps and genomic data at the same time, to discover new genes that affect brain organization and disease risk (see Jahanshad et al., 2013c; Thompson et al., 2013).

One of the main issues with imaging genetics is sample size. Well over a million commonlycarried variants in the genome - including, for example, single nucleotide polymorphisms, or SNPs - can be assessed using widely available technology for performing genome-wide scans. For many years, vast studies that have searched for SNPs that are over-represented in patients with certain types of disease. These genome-wide association scans (GWAS) need notoriously large samples because the effect of any one SNP is usually small (Jahanshad et al., 2013d).

The high risk of false positives when scouring the genome makes it necessary to amass huge samples to confirm any promising results, or to use complex methods to reduce the dimension of the search space (Silver et al., 2012; Hibar et al., 2013a,b). In the past few years, very large imaging genetics consortia have been formed with sample sizes numbering tens of thousands of subjects - enough subjects to pick up the effects of single letter changes in the genome on features derived from brain images. In these consortium efforts, multiple sites pool their data to increase the chances of finding significant associations between genetic variants and brain measures. One of the largest imaging genetics networks is the ENIGMA Consortium (Enhancing Neuroimaging Genetics through Meta-Analysis). This is an effort between 125 institutions across 12 countries, analyzing over 21,000 scans at the time of writing. This dataset has already been used to discover genes that affect brain structure, for example in the hippocampus (Stein et al., 2012), and jointly analyzing DTI data from thousands of subjects (Kochunov et al., 2012; Jahanshad et al., 2013b). The advantage of these efforts for studies of brain connectivity is that many connectivity measures are still poorly understood, so even the most general statements about changes in network efficiency must be confirmed and tested across developmental samples worldwide. This is particularly important in genetics, as a huge number of candidate genes have been asserted to affect brain maturation but findings are not always consistent.

Many studies have related specific genetic variants to individual differences in white matter integrity, as measured by FA (Braskie et al., 2011; Kohannim et al., 2011, McIntosh et al., 2008; Winterer et al., 2008). With greater subject numbers, consortia such as ENIGMA are beginning to offer the sample sizes needed to discover specific genes influencing brain connectivity. Studies in both healthy subjects (Buckholtz et al., 2007; Buckholtz et al., 2008; Pezawas et al., 2005; Thomason et al., 2009) and those with neurodevelopmental or neuropsychiatric disorders (Meyer-Lindenberg et al., 2007; Scott-Van Zeeland et al., 2010) have found associations between specific genetic variants and changes in functional connectivity; clearly, large samples are needed to allow meta-analysis and corroboration of these subtle effects.

\section{Functional and Structural Connectivity}

Some researchers have begun to investigate the link between functional and structural connectivity, but only one study that the authors are aware of has examined the joint effects age has on structural and functional connectivity. In addition to the age effects seen in functional and structural connectivity separately that are discussed above, Supekar et al. (2010) also found an age difference in the relationship between functional and structural connectivity. When examining the connection between the PCC and mPFC, Supekar et al. (2010) found a significantly positive partial correlation between the functional time courses and fiber densities between the ROIs. There was no significant relationship between partial correlation strength and fiber density in the PCC-mPFC connection in children. Structural 
and functional connectivity are closely related, but one does not imply the other - regions that are structurally connected are also functionally correlated, but two regions that are functionally connected are not necessarily directly structurally linked (Greicius et al., 2008; Bullmore and Sporns, 2009; Honey et al., 2009). Very little work has been done on the question of how alterations of the structural network are correlated with alterations in the functional networks (Rudie et al., 2013). As functional connectivity may arise between areas with no direct structural connection, further investigation is necessary into how these complementary systems interact.

\section{Other Methods}

In this review, space limitations meant that we did not cover the literature addressing development using MEG (magnetoencephalography) or EEG (electroencephalography). A number of studies have examined developmental changes in MEG or EEG signals (MeyerLindenberg, 1996; Polonnikov et al., 2003; Eswaran et al., 2004). These data can also be used to examine brain connectivity. By examining the coherence between MEG or EEG signals across the brain, connectivity can be assessed (Bullmore \& Sporns, 2009). One study has even linked EEG-based networks to intelligence (Langer et al., 2012). As several studies have reported developmental effects on MEG and EEG signals, and the link between EEG network measures and cognition, examining the developmental trajectory of MEG- and EEG-based networks would be of great interest.

\section{Conclusions}

Dramatic changes occur in the structural and functional connectivity of the brain, as it matures into adulthood. Structural and functional connectivity both support healthy brain function - a disruption in either can lead to a neurodevelopmental or neuropsychiatric disorder. Characterizing the developmental trajectory of these measures in healthy subjects serves an important function in understanding disease and in understanding the fundamental processes by which the brain matures. Here we have detailed a number of studies that examined the developmental trajectory of various measures of structural or functional connectivity in typically developing subjects. We also discussed a few examples of research into how structural and functional connectivity can be affected in developmental disorders. We also discussed a few of the themes commonly considered in connectivity, from developmental point of view - the structure-function relationship, asymmetry, and sex differences, and some future directions for the field.

\section{Acknowledgments}

ED was funded, in part, by an NIH Training Grant in Neurobehavioral Genetics (T32MH073526-06). Our work on brain connectivity reported here is supported in part by the National Institute of Child Health and Human Development (R01 HD050735), and the National Health and Medical Research Council (NHMRC 486682, 1009064), Australia. Additional support for algorithm development was provided by NIH R01 grants EB008432, EB008281, EB007813 and P41 RR013642.

\section{References}

Aganj I, Lenglet C, Jahanshad N, Yacoub E, Harel N, Thompson PM, Sapiro G. A Hough transform global probabilistic approach to multiple-subject diffusion MRI tractography. Medical Image Analysis. 2011; 15(4):414-425. [PubMed: 21376655]

Anderson JC, Williams S, McGee R, Silva PA. DSM-III disorders in preadolescent children. Prevalence in a large sample from the general population. Arch Gen Psych. 1987; 44(1):69-76.

Arlinghaus LR, Thornton-Wells TA, Dykens EM, Anderson AW. Alterations in diffusion properties of white matter in Williams syndrome. Magnetic Resonance Imaging. 2011; 29(9):1165-1174.

[PubMed: 21907520] 
Asato MR, Terwilliger R, Woo J, Luna B. White Matter Development in Adolescence: A DTI Study. Cerebral Cortex. 2010; 20(9):2122-2131. [PubMed: 20051363]

Ashtari M, Kumra S, Bhaskar SL, Clarke T, Thaden E, Cervellione KL, Rhinewine J, Kane JM, Adesman A, Milanaik R, Maytal J, Diamond A, Szeszko P, Ardekani BA. Attention-deficit/ hyperactivity disorder: A preliminary diffusion tensor imaging study. Biological Psychiatry. 2005; 57(5):448-455. [PubMed: 15737658]

Barnea-Goraly N, Eliez S, Hedeus M, Menon V, White CD, Moseley M, Reiss AL. White matter tract alterations in fragile $\mathrm{X}$ syndrome: Preliminary evidence from diffusion tensor imaging. American Journal of Medical Genetics Part B: Neuropsychiatric Genetics. 2003; 118B(1):81-88.

Barnea-Goraly N, Kwon H, Menon V, Eliez S, Lotspeich L, Reiss AL. White matter structure in autism: preliminary evidence from diffusion tensor imaging. Biological Psychiatry. 2004; 55(3): 323-326. [PubMed: 14744477]

Barnea-Goraly N, Lotspeich L, Reiss A. Similar White Matter Aberrations in Children With Autism and Their Unaffected Siblings: A Diffusion Tensor Imaging Study Using Tract-Based Spatial Statistics. Archives of General Psychiatry. 2010; 67(10):1052-1060. [PubMed: 20921121]

Barnea-Goraly N, Menon V, Eckert M, Tamm L, Bammer R, Karchemskiy A, Dant CC, Reiss AL. White Matter Development During Childhood and Adolescence: A Cross-sectional Diffusion Tensor Imaging Study. Cerebral Cortex. 2005; 15:1848-1854. [PubMed: 15758200]

Beckmann CF, DeLuca M, Devlin JT, Smith SM. Investigations into resting-state connectivity using independent component analysis. Philosophical Transactions of the Royal Society. 2005; 360:1001-1013.

Ben Bashat D, Ben Sira L, Graif M, Pianka P, Hendler T, Cohen Y, Assaf Y. Normal white matter development from infancy to adulthood: comparing diffusion tensor and high $\mathrm{b}$ value diffusion weighted MR images. Journal of Magnetic Resonance Imaging. 2005; 21(5):503-511. [PubMed: 15834918]

Ben Bashat D, Kronfeld-Duenias V, Zachor DA, Ekstein PM, Hendler T, Tarrasch R, Even A, Levy Y, Ben Sira L. Accelerated maturation of white matter in young children with autism: A high $b$ value DWI study. NeuroImage. 2007; 37:40-47. [PubMed: 17566764]

Biederman J. Attention-Deficit/Hyperactivity Disorder: A Selective Overview. Biol Psychiat. 2005; 57:1215-20. [PubMed: 15949990]

Biswal B, Yetkin FZ, Haughton VM, Hyde JS. Functional connectivity in the motor cortex of resting human brain using echo-planar MRI. Magn Res Med. 1995; 34:537-541.

Braskie M, Jahanshad N, Stein J, Barysheva M, McMahon K, de Zubicaray GI, Martin NG, Wright MJ, Ringman JM, Toga AW, Thompson PM. Common Alzheimer's Disease Risk Variant Within the CLU Gene Affects White Matter Microstructure in Young Adults. J of Neuroscience. 2011; 31:6764-6770.

Bray S, Dunkin B, Hong DS, Reiss AL. Reduced Functional Connectivity during Working Memory in Turner Syndrome. Cerebral Cortex. 2011; 21(11):2471-2481. [PubMed: 21441396]

Bray S, Hoeft F, Hong DS, Reiss AL. Aberrant functional network recruitment of posterior parietal cortex in turner syndrome. Human Brain Mapping. 2012 Jun 19. [Epub ahead of print].

Brun CC, Luders E, Lepore N, Chou YY, Madsen SK, Toga AW, Thompson PM. Sex differences in brain structure in auditory and cingulate regions. NeuroReport. 2009; 20(10):930-5. [PubMed: 19562831]

Buckholtz JW, Callicott JH, Kolachana B, Hariri AR, Golberg TE, Gendersen M, Egan MF, Mattay VS, Weinberger DR, Meyer-Lindenberg A. Genetic variation in MAOA modulates ventromedial prefrontal circuitry mediating individual differences in human personality. Molecular Psychiatry. 2008; 13:313-324. [PubMed: 17519928]

Buckholtz JW, Meyer-Lindenberg A, Honea RA, Straub RE, Pezawas L, Egan MF, Vakkalanka R, Kolachana B, Verchinski BA, Sust S, Mattay VS, Weinberger DR, Callicott JH. Allelic Variation in RGS4 Impacts Functional and Structural Connectivity in the Human Brain. Journal of Neuroscience. 2007; 27(7):1584-1593. [PubMed: 17301167]

Buckner RL, Andrews-Hanna JR, Schacter DL. The Brain's Default Network: Anatomy, Function, and Relevance to Disease. Annals of the New York Academy of Sciences. 2008; 1124(1):1-38. [PubMed: 18400922] 
Bullmore E, Sporns O. Complex brain networks: graph theoretical analysis of structural and functional systems. Nature Reviews Neuroscience. 2009; 10(3):186-198.

Cao Q, Zang Y, Sun L, Sui M, Long X, Zou Q, Wang Y. Abnormal neural activity in children with attention deficit hyperactivity disorder: a resting- state functional magnetic resonance imaging study. NeuroReport. 2006; 17(10):1033-1036. [PubMed: 16791098]

Cascio CJ, Gerig G, Piven J. Diffusion Tensor Imaging: Application to the Study of the Developing Brain. J Am Acad Child Adolesc Psychiatry. 2007; 46(2):213-223. [PubMed: 17242625]

Casey B, Giedd JN, Thomas KM. Structural and functional brain development and its relation to cognitive development. Biological Psychiatry. 2000; 54:241-257.

Castellanos FX, Margulies DS, Kelly C, Uddin LQ, Ghaffari M, Kirsch A, Shaw D, Shehzad Z, Di Martino A, Biswal B, Sonuga-Barke EJS, Rotrosen J, Adler LA, Milham MP. CingulatePrecuneus Interactions: A New Locus of Dysfunction in Adult Attention-Deficit/Hyperactivity Disorder. Biological Psychiatry. 2008; 63(3):332-337. [PubMed: 17888409]

Cetingul, HE.; Afsari, Bijan; Wright, Margaret; Thompson, Paul; Vidal, Rene. ISBI 2012. Barcelona, Spain: 2012a May 2-5. A Riemannian Framework For Processing Orientation Distribution Functions On The Joint Orientation And Shape Space. 2012

Cetingul HE, Sapiro G, Nadar M, Paul M, Thompson, Lenglet C. Simultaneous ODF Estimation and Robust Probabilistic Tractography from HARDI. MICCAI CDMRI 2012. 2012b accepted.

Cherkassky VL, Kana RK, Keller TA, Just MA. Functional connectivity in a baseline resting-state network in autism. NeuroReport. 2006; 17:1687-1690. [PubMed: 17047454]

Chiang MC, McMahon KL, de Zubicaray GI, Martin NG, Hickie I, Toga AW, Wright MJ, Thompson PM. Genetics of white matter development: A DTI study of 705 twins and their siblings aged 12 to 29. NeuroImage. 2011; 54(3):2308-2317. [PubMed: 20950689]

Chiang MC, Reiss AL, Lee AD, Bellugi U, Galaburda AM, Korenberg J, Mills DL, Toga AW, Thompson PM. 3D Pattern of Brain Abnormalities in Williams Syndrome Visualized using Tensor-Based Morphometry. NeuroImage. 2007 Apr 20. [Epub ahead of print].

Daianu, M.; Jahanshad, N.; Dennis, EL.; Toga, AW.; McMahon, KL.; de Zubicaray, GI.; Wright, MJ.; Hickie, I.; Thompson, PM. ISBI 2012. Barcelona, Spain: 2012 May 2-5. Left Versus Right Hemisphere Differences In Brain Connectivity: 4-Tesla HARDI Tractography In 567 Twins.

Damoiseaux JS, Rombouts SARB, Barkhof F, Scheltens P, Stam CJ, Smith SM, Beckmann CF. Consistent resting-state networks across healthy subjects. PNAS. 2006; 103(37):13848-13853. [PubMed: 16945915]

Debbané M, Lazouret M, Lagioia A, Schneider M, Van de Ville D, Eliez S. Resting-state networks in adolescents with 22q11.2 deletion syndrome: Associations with prodromal symptoms and executive functions. Schizophrenia Research. 2012; 139:33-39. [PubMed: 22704643]

Dennis EL, Jahanshad N, McMahon KL, de Zubicaray GI, Martin NG, Hickie IB, Toga AW, Wright MJ, Thompson PM. Development of brain structural connectivity between ages 12 and 30: A 4Tesla diffusion imaging study in 439 adolescents and adults. NeuroImage. 2013; 64:671-684. [PubMed: 22982357]

Dennis EL, Jahanshad N, Toga AW, Rudie JD, Dapretto M, Brown JA, Bookheimer SY, Johnson K, McMahon KL, de Zubicaray GI, Montgomery G, Martin NG, Wright MJ, Thompson PM. Abnormal Structural Brain Connectivity in Healthy Carriers of the Autism Risk Gene, CNTNAP2. Brain Connectivity. 2012 published online, 2012.

Dimond \& Beaumont. Hemisphere Function in the Human Brain. John Wiley \& Sons; Oxford, England: 1974.

Dosenbach NUF, Nardos B, Cohen AL, Fair DA, Power JD, Church JA, Nelson SM, Wig GS, Vogel AC, Lessov-Schlaggar CN, Barnes KA, Dubis JW, Feczko E, Coalson RS, Pruett JR, Barch DM, Petersen SE, Schlaggar BL. Prediction of Individual Brain Maturity Using fMRI. Science. 2010; 329(5997):1358-1361. [PubMed: 20829489]

Eckert MA, Galaburda AM, Karchemskiy A, Liang A, Thompson PM, Dutton RA, Lee AD, Bellugi U, Korenberg JR, Mills DL, Rose F, Reiss AL. Anomalous Sylvian Fissure Morphology in Williams Syndrome. NeuroImage. 2006 published online, July 282006.

Engel JP, Thompson PM, Stern JM, Staba RJ, Bragin A, Mody I. Connectomics and Epilepsy. Current Opinion in Neurology. 2013; 26(2):186-194. [PubMed: 23406911] 
Eswaran H, Lowery CL, Wilson JD, Murphy P, Preissl H. Functional development of the visual system in human fetus using magnetoencephalography. Experimental Neurology. 190:52-58.

Fair DA, Cohen AL, Dosenbach NUF, Church JA, Miezin FM, Barch DM, Raichle ME, Petersen SE, Schlaggar BL. The maturing architecture of the brain's default network. Proceedings of the National Academy of Sciences. 2008; 105(10):4028-4032.

Fair DA, Cohen AL, Power JD, Dosenbach NUF, Church JA, Miezin FM, Schlaggar BL, Petersen SE. Functional brain networks develop from a "local to distributed" organization. PLoS computational biology. 2009; 5(5):e1000381. [PubMed: 19412534]

Fair DA, Dosenbach NUF, Church JA, Cohen AL, Brahmbhatt S, Miezin FM, Barch DM, Raichle ME, Petersen SE, Schlaggar BL. Development of distinct control networks through segregation and integration. PNAS. 2007; 104(33):13507-13512. [PubMed: 17679691]

Fan Y, Shi F, Smith JK, Lin W, Gilmore JH, Shen D. Brain anatomical networks in early human brain development. NeuroImage. 2011; 54(3):1862-1871. [PubMed: 20650319]

Fox MD, Raichle ME. Spontaneous fluctuations in brain activity observed with functional magnetic resonance imaging. Nature Reviews Neuroscience. 2007; 8(9):700-711.

Fox MD, Snyder AZ, Vincent JL, Corbetta M, Essen DCV, Raichle ME. The human brain is intrinsically organized into dynamic, anticorrelated functional networks. PNAS. 2005; 102(27): 9673-9678. [PubMed: 15976020]

Fransson P, Skiöld B, Horsch S, Nordell A, Blennow M, Lagercrantz H, Aden U. Resting-state networks in the infant brain. PNAS. 2007; 104(39):15531-15536. [PubMed: 17878310]

Gaser C, Luders E, Thompson PM, Lee AD, Dutton RA, Geaga JA, Hayashi KM, Bellugi U, Galaburda AM, Korenberg JR, Mills DL, Toga AW, Reiss AL. Increased Local Gyrification Mapped in Williams Syndrome. NeuroImage. 2006 Oct 15; 33(1):46-54. Epub 2006 Aug 9. [PubMed: 16901723]

Gao W, Lin W, Chen Y, Gerig G, Smith JK, Jewells V, Gilmore JH. Temporal and spatial development of axonal maturation and myelination of white matter in the developing brain. AJNR. 2009a; 30(2):290-296. [PubMed: 19001533]

Gao W, Zhu H, Giovanello KS, Smith JK, Shen D, Gilmore JH, Lin W. Evidence on the emergence of the brain's default network from 2-week-old to 2-year-old healthy pediatric subjects. PNAS. 2009b; 106(16):6790-6795. [PubMed: 19351894]

Giedd JN, Blumenthal J, Jeffries NO, Castellanos FX, Liu H, Zijdenbos A, Paus T, Evans AC, Rapoport JL. Brain development during childhood and adolescence: a longitudinal MRI study. Nature Neuroscience. 1999; 2(10):861-863.

Giedd JN, Vaituzis AC, Hamburger SD, Lange N, Rajapakse JC, Kaysen D, Vauss YC, Rapoport JL. Quantitative MRI of the Temporal Lobe, Amygdala, and Hippocampus in Normal Human Development: Ages 4-18 Years. Journal of Comparative Neurology. 1996; 355:223-230. [PubMed: 8698883]

Gilmore JH, Lin W, Prastawa MW, Looney CB, Vetsa YSK, Knickmeyer RC, Evans DD, Smith JK, Hamer RM, Lieberman JA, Gerig G. Regional gray matter growth, sexual dimorphism, and cerebral asymmetry in the neonatal brain. Journal of Neuroscience. 2007; 27(6):1255-1260. [PubMed: 17287499]

Gilmore JH, Zhai G, Wilber K, Smith JK, Lin W, Gerig G. 3 Tesla magnetic resonance imaging of the brain in newborns. Psychiatry research. 2004; 132(1):81-85. [PubMed: 15546705]

Giorgio A, Watkins KE, Douaud G, James AC, James S, De Stefano N, Matthews PM, Smith SM, Johansen-Berg H. Changes in white matter microstructure during adolescence. NeuroImage. 2008; 39:52-61. [PubMed: 17919933]

Glahn DC, Paus T, Thompson PM. Imaging Genomics: Mapping the Influence of Genetics on Brain Structure and Function, Human Brain Mapping. Special Issue on Genomic Imaging. 2007 published online, April 172007.

Gogtay N, Giedd JN, Lusk L, Hayashi KM, Greenstein D, Vaituzis AC, Nugent TF III, Herman DH, Clasen LS, Toga AW, Rapoport JL, Thompson PM. Dynamic mapping of human cortical development during childhood through early adulthood. PNAS. 2004; 101(21):8174-8179. [PubMed: 15148381] 
Gong G, He Y, Evans AC. Brain connectivity: Gender makes a difference. The Neuroscientist. 2011; 17(5):575-591. [PubMed: 21527724]

Gong G, Rosa-Neto P, Carbonell F, Chen ZJ, He Y, Evans AC. Age- and Gender-Related Differences in the Cortical Anatomical Network. Journal of Neuroscience. 2009; 29(50):15684-15693. [PubMed: 20016083]

Greicius M. Resting-state functional connectivity in neuropsychiatric disorders. Current Opinion in Neurology. 2008; 21:424-430. [PubMed: 18607202]

Gur RC, Turetsky BI, Matsui M, Yan M, Bilker W, Hughett P, Gur RE. Sex Differences in Brain Gray and White Matter in Healthy Young Adults: Correlations with Cognitive Performance. Journal of Neuroscience. 1999; 19(10):4065-4072. [PubMed: 10234034]

Haas BW, Barnea-Goraly N, Lightbody AA, Patnaik SS, Hoeft F, Hazlett H, Piven J, Reiss AL. Early white -matter abnormalities of the ventral frontostriatal pathway in fragile $\mathrm{X}$ syndrome. Developmental Medicine and Child Neurology. 2009; 51(8):593-599. [PubMed: 19416325]

Haas BW, Hoeft F, Barnea-Goraly N, Golarai G, Bellugi U, Reiss AL. Preliminary evidence of abnormal white matter related to the fusiform gyrus in Williams syndrome: a diffusion tensor imaging tractography study. Genes, Brain and Behavior. 2011; 11(1):62-68.

Hagmann P, Sporns O, Madan N, Cammoun L, Pienaar R, Wedeen VJ, Meuli R, Thiran JP, Grant PE. White matter maturation reshapes structural connectivity in the late developing human brain. PNAS. 2010; 107(44):19067-19072. [PubMed: 20956328]

Hamilton LS, Levitt JG, O’Neill J, Alger JR, Luders E, Phillips OR, Caplan R, Toga AW, McCracken J, Narr K. Reduced white matter integrity in attention-deficit hyperactivity disorder. NeuroReport. 2008; 19(17):1705-1708. [PubMed: 18841089]

Hasan KM, Iftikhar A, Kamali A, Kramer LA, Ashtari M, Cirino PT, Papanicolaou AC, Fletcher JM, Ewing-Cobbs L. Development and aging of the healthy human brain uncinate fasciculus across the lifespan using diffusion tensor tractography. Brain Research. 2009a; 1276:67-76. [PubMed: 19393229]

Hasan KM, Kamali A, Iftikhar A, Kramer LA, Papanicolaou AC, Fletcher JM, Ewing-Cobbs L. Diffusion tensor tractography quantification of the human corpus callosum fiber pathways across the lifespan. Brain Research. 2009b; 1249:91-100. [PubMed: 18996095]

Hellige, JB. Hemispheric asymmetry: What's right and what's left. Harvard University Press; Cambridge, MA: 1993.

Hibar, D.; Medland, SE.; Stein, JL.; Kim, S.; Shen, L.; Saykin, AJ.; de Zubicaray, GI.; McMahon, KL.; Montgomery, GW.; Martin, NG.; Wright, MJ.; Djurovic, S.; Agartz, I.; Andreassen, OA.; Thompson, PM. Genetic clustering on the hippocampal surface for genome-wide association studies. Submitted to MICCAI 2013; Nagoya, Japan. Sept. 22-26 2013; 2013. [8-page paper; peerreviewed]

Hibar, D.; Stein, JL.; Jahanshad, N.; Toga, AW.; McMahon, KL.; de Zubicaray, GI.; Montgomery, GW.; Martin, NG.; Wright, MJ.; Weiner, MW.; Thompson, PM. Exhaustive search of the SNPSNP interactome identifies replicated epistatic effects on brain volume. Submitted to MICCAI 2013; Nagoya, Japan. Sept. 22-26 2013; 2013. [8-page paper; peer-reviewed]

Hoeft F, Barnea-Goraly N, Haas BW, Golarai G, Ng D, Mills D, Korenberg J, Bellugi U, Galaburda A, Reiss AL. More Is Not Always Better: Increased Fractional Anisotropy of Superior Longitudinal Fasciculus Associated with Poor Visuospatial Abilities in Williams Syndrome. Journal of Neuroscience. 2007; 27(44):11960-11965. [PubMed: 17978036]

Holzapfel M. Selective Alterations of White Matter Associated with Visuospatial and Sensorimotor Dysfunction in Turner Syndrome. Journal of Neuroscience. 2006; 26(26):7007-7013. [PubMed: 16807330]

Honey C, Sporns O, Cammoun L, Gigandet X, Thiran J, Meuli R, Hagmann P. Predicting human resting-state functional connectivity from structural connectivity. PNAS. 2009; 106(6):2035-2040. [PubMed: 19188601]

Huttenlocher P. Morphometric study of human cerebral cortex development. Neuropsychologia. 1990; 28(6):517-527. [PubMed: 2203993]

Huttenlocher PR, Dabholkar AS. Regional Differences in Synaptogenesis in Human Cerebral Cortex. The Journal of Comparative Neurology. 1997; 387:167-178. [PubMed: 9336221] 
Jabbi M, Kippenhan JS, Kohn P, Marenco S, Mervis CB, Morris CA, Meyer-Lindenberg A, Berman KF. The Williams syndrome chromosome 7q11.23 hemideletion confers hypersocial, anxious personality coupled with altered insula structure and function. PNAS. 2012:e860-e866. [PubMed: 22411788]

Jahanshad N, Aganj I, Lenglet C, Jin Y, Joshi A, Barysheva M, McMahon KL, de Zubicaray GI, Martin NG, Wright MJ, Toga AW, Sapiro G, Thompson PM. High angular resolution diffusion imaging (HARDI) tractography in 234 young adults reveals greater frontal lobe connectivity in women. ISBI. 2011; 2011

Jahanshad, N.; Kochunov, P.; Glahn, D.; Blangero, J.; Nichols, TE.; McMahon, KL.; de Zubicaray, GI.; Martin, NG.; Wright, MJ.; Nir, T.; Jack, CR., Jr; Weiner, MW.; Toga, AW.; Thompson, PM. the ADNI. Power Estimates for Voxel-Based Genetic Association Studies using Diffusion Imaging. Submitted to MICCAI 2013; Nagoya, Japan. Sept. 22-26 2013; 2013d. [8-page paper; peer-reviewed]

Jahanshad N, Kochunov P, Sprooten E, Mandl RC, Nichols TE, Booth T, Blangero J, de Zubicaray GI, Hong EL, Landman BA, Martin NG, McMahon KL, Medland SE, Mitchell BD, Peterson CP, Star JM, Sussmann JE, Toga AW, Wardlaw JM, Wright MJ, Hulshoff Pol HE, Bastin ME, McIntosh AM, Deary IJ, Thompson PM, Glahn DC. Multi-Site Genetic Analysis of Diffusion Images and Voxelwise Heritability Analysis: A Pilot Project of the ENIGMA-DTI Working Group. NeuroImage. 2013b submitted, Jan 2013.

Jahanshad N, Kohannim O, Hibar DP, Stein JL, McMahon KL, de Zubicaray GI, Medland SE, Montgomery G, Whitfield JB, Martin NG, Wright MJ, Toga AW, Thompson PM. Brain structure in healthy adults is related to serum transferrin and the H63D polymorphism in the HFE gene. PNAS. 2012; 109(14):e851-e859. [PubMed: 22232660]

Jahanshad N, Rajagopalan P, Thompson P. Neuroimaging, Nutrition, and Iron-Related Genes. Invited Review for Cellular Molecular and Life Science Reviews (CMLS Reviews). 2013a submitted, Feb 42013.

Jahanshad N, Toga AW, McMahon KL, de Zubicaray GI, Martin NG, Wright MJ, Thompson PM. Conne ctome-Wide Genome-Wide Search Discovers SPON1 Gene Variant Influencing Dementia Severity. PNAS. 2013c Feb.

Jahanshad, N.; Zhan, L.; Bernstein, MA.; Borowski, B.; Jack, CR.; Toga, AW.; Thompson, PM. Diffusion Tensor Imaging in Seven Minutes: Determining Trade-Offs Between Spatial and Directional Resolution. ISBI 2010; Rotterdam, The Netherlands. April 14-17, 2010; 2010. [4 pages; peer-reviewed paper]

Jin Y, Shi Y, Zhan L, Li J, de Zubicaray GI, McMahon KL, Martin NG, Wright MJ, Thompson PM. Automatic Population HARDI White Matter Tract Clustering by Label Fusion of Multiple Tract Atlases. MICCAI MBIA Workshop 2012. 2012 accepted.

Just MA, Cherkassky VL, Keller TA, Kana RK, Minshew NJ. Functional and Anatomical Cortical Underconnectivity in Autism: Evidence from an fMRI Study of an Executive Function Task and Corpus Callosum Morphometry. Cerebral Cortex. 2007; 17(4):951-961. [PubMed: 16772313]

Kelly AMC, Di Martino A, Uddin LQ, Shehzad Z, Gee DG, Reiss PT, Margulies DS, Castellanos FX, Milham MP. Development of anterior cingulate functional connectivity from late childhood to early adulthood. Cerebral Cortex. 2009; 19(3):640-657. [PubMed: 18653667]

Kennedy DP, Courchesne E. The intrinsic functional organization of the brain is altered in autism. NeuroImage. 2008; 39:1877-1885. [PubMed: 18083565]

Kesler SR. Turner Syndrome. Child Adolesc Psychiatr Clin N Am. 2007; 16(3):709-722. [PubMed: 17562588]

Kilpatrick LA, Zald DH, Pardo JV, Cahill LF. Sex-related differences in amygdala functional connectivity during resting conditions. NeuroImage. 2006; 30:452-461. [PubMed: 16326115]

Kimura, D. Sex and Cognition. MIT Press; Cambridge, MA: 2000.

Knickmeyer RC, Gouttard S, Kang C, Evans D, Wilber K, Smith JK, Hamer Robert M, Lin W, Gerig G, Gilmore JH. A Structural MRI Study of Human Brain Development from Birth to 2 Years. The Journal of Neuroscience. 2008; 28(47):12176-12182. [PubMed: 19020011]

Kochunov, P.; Jahanshad, N.; Sprooten, E.; Thompson, P.; McIntosh, A.; Deary, I.; Bastin, M.; Toga, A.; McMahon, K.; de Zubicaray, G.; Martin, N.; Wright, M.; Montgomery, G.; Medland, S.; 
Carless, M.; Curran, J.; Hong, E.; Duggirala, R.; Olvera, R.; Dyer, T.; Blangero, J.; Glahn, D. Genome-wide association of full brain white matter integrity - from the ENIGMA DTI working group. Presented at the 18th Annual Meeting of the Organization for Human Brain Mapping; Beijing, China. June 10-14, 2012; 2012.

Kochunov P, Williamson DE, Lancaster J, Fox P, Cornell J, Blangero J, Glahn DC. Fractional anisotropy of water diffusion in cerebral white matter across the lifespan. Neurobiology of Aging. 2010:1-12.

Kohannim O, Jahanshad N, Braskie MN, Stein JL, Chiang M-C, Reese AH, Hibar DP, Toga AW, McMahon KL, de Zubicaray GI, Medland SE, Wright MJ, Thompson PM. Personalized prediction of white matter integrity by genotyping multiple common genetic variants ( $\mathrm{N}=395$ DTI study). Molecular Psychiatry. 2011 Submitted.

Konrad A, Dielentheis TF, Masri EID, Bayerl M, Fehr C, Gesierich T, Vucurevic G, Stoeter P, Winterer G. Disturbed structural connectivity is related to inattention and impulsivity in adult attention deficit hyperactivity disorder. European Journal of Neuroscience. 2010; 31(5):912-919. [PubMed: 20374289]

Langer N, Pedroni A, Gianotti LRR, Hänggi J, Knoch D, Jäncke L. Functional brain network efficiency predicts intelligence. Human Brain Mapping. 2012; 33(6):1393-1406. [PubMed: 21557387]

Li Q, Sun J, Guo L, Zang Y, Feng Z, Huang X, Yang H, Lv Y, Huang M, Gong Q. Increased Fractional Anisotropy in White Matter of the Right Frontal Region in Children with AttentionDeficit/Hyperactivity Disorder: A Diffusion Tensor Imaging Study. Activitas Nervosa Superior Rediviva. 2011; 52(3):193-199.

Lim KO, Helpern JA. Neuropsychiatric applications of DTI - a review. NMR in Biomedicine. 2002; 15(7-8):587-593. [PubMed: 12489105]

Lin W, Zhu Q, Gao W, Chen Y, Toh CH, Styner M, Gerig G, Smith JK, Biswal B, Gilmore JH. Functional connectivity MR imaging reveals cortical functional connectivity in the developing brain. AJNR. 2008; 29(10):1883-1889. [PubMed: 18784212]

Liu WC, Flax JF, Guise KG, Sukul V, Benasich AA. Functional connectivity of the sensorimotor area in naturally sleeping infants. Brain Research. 2008; 1223:42-49. [PubMed: 18599026]

Luders E, Di Paola M, Tomaiuolo F, Thompson PM, Toga AW, Vicari S, Petrides M, Caltagirone C. Callosal Morphology In Williams Syndrome - A New Evaluation Of Shape And Thickness. Neuroreport. 2007 Feb; 18(3):203-207. [PubMed: 17314657]

Luders E, Narr KL, Hamilton LS, Phillips OR, Thompson PM, Valle JS, Del'Homme M, Strickland T, Toga AW, McCracken JT, Levitt JG. Decreased Callosal Thickness in Attention Deficit/ Hyperactivity Disorder (ADHD). Biological Psychiatry. 2008 Oct 6. [Epub ahead of print].

Luders E, Toga A, Thompson P. Why Size Matters: Differences in Brain Volume Account for Apparent Sex Differences in Callosal Anatomy. Human Brain Mapping. 2013 submitted, March 2013.

Makris N, Buka SL, Biederman J, Papadimitriou GM, Hodge SM, Valera EM, Brown AB, Bush G, Moneteaux MC, Caviness VS, Kennedy DN, Seidman LJ. Attention and Executive Systems Abnormalities in Adults with Childhood ADHD: A DT-MRI Study of Connections. Cerebral Cortex. 2007; 18(5):1210-1220. [PubMed: 17906338]

McGlone J. Sex differences in brain asymmetry. Cortex. 1978; 14(1):122-128. [PubMed: 16295117]

McGlone J. Sex differences in human brain asymmetry: a critical survey. Behavioral and Brain Sciences. 1980; 3:215-227.

McIntosh AM, Moorhead TWJ, Job D, Lymer GKS, Muñoz Maniega S, McKirdy J, Sussman JED, Baig BJ, Bastin ME, Porteous D, Evans KL, Johnstone EC, Lawrie S, Hall JM. The effects of a neuregulin 1 variant on white matter density and integrity. Molecular Psychiatry. 2008; 13:10541059. [PubMed: 17925794]

McLaughlin NCR, Paul RH, Grieve SM, Williams LM, Laidlaw D, DiCarlo M, Clark CR, Whelihan W, Cohen RA, Whitford TJ, Gordon E. Diffusion tensor imaging of the corpus callosum: a crosssectional study across the lifespan. International journal of developmental neuroscience. 2007; 25(4):215-221. [PubMed: 17524591] 
Meyer-Lindenberg A. The evolution of complexity in human brain development: An EEG study. Electroencephalography and Clinical Neurophysiology. 1996; 99(5):405-411. [PubMed: 9020798]

Meyer-Lindenberg A, Straub RE, Lipska BK, Verchinski BA, Golberg T, Callicott JH, Egan MF, Huffaker SS, Mattay VS, Kolachana B, Kleinman JE, Weinberger DR. J Clin Invest. 2007; 117(3):672-682. [PubMed: 17290303]

Molko N. Brain Anatomy in Turner Syndrome: Evidence for Impaired Social and Spatial-Numerical Networks. Cerebral Cortex. 2004; 14(8):840-850. [PubMed: 15054057]

Monk CS, Peltier SJ, Wiggins JL, Weng SJ, Carrasco M, Risi S, Lord C. Abnormalities of intrinsic functional connectivity in autism spectrum disorders. NeuroImage. 2009; 47(2):764-772. [PubMed: 19409498]

Morriss MC, Zimmerman RA, Bilaniuk LT, Hunter JV. Changes in brain water diffusion during childhood. Neuroradiology. 1999; 41:929-934. [PubMed: 10639670]

Mukherjee P, Miller JH, Shimony JS, Conturo TE, Lee BC, Almli CR, McKinstry RC. Normal brain maturation during childhood: developmental trends characterized with diffusion-tensor MR imaging. Radiology. 2001; 221(2):349-358. [PubMed: 11687675]

Mullaney, R.; Murphy, D. Turner syndrome: Neuroimaging findings: Structural and functional. In: Ross, J.; Hoeft, F., editors. Developmental Disabilities Research Reviews. Vol. 15. 2009. p. 279-283.

Noonan SK, Haist F, Müller RA. Aberrant functional connectivity in autism: Evidence from lowfrequency BOLD signal fluctuations. Brain Research. 2009; 1262(C):48-63. [PubMed: 19401185]

Pavuluri MN, Yang S, Kamineni K, Passarotti AM, Srinivasan G, Harral EM, Sweeney JA, Zhou XJ. Diffusion Tensor Imaging Study of White Matter Fiber Tracts in Pediatric Bipolar Disorder and Attention-Deficit/Hyperactivity Disorder. BPS. 2009; 65(7):586-593.

Pezawas L, Meyer-Lindenberg A, Drabant EM, Verchinski BA, Munoz KE, Kolachana BS, Egan MF, Mattay VS, Hariri AR, Weinberger DR. 5-HTTLPR polymorphism impacts human cingulateamygdala interactions: a genetic susceptibility mechanism for depression. Nature Neuroscience. 2005; 8:828-834.

Polonnikov RI, Wasserman EL, Kartashev NK. Regular developmental changes in EEG multifractal characteristics. International Journal of Neuroscience. 2003; 113(11):1615-1639. [PubMed: 14585757]

Power JD, Fair DA, Schlaggar BL, Petersen SE. The Development of Human Functional Brain Networks. Neuron. 2010; 67:735-748. [PubMed: 20826306]

Raichle ME, MacLeod AM, Snyder AZ, Powers WJ, Gusnard DA, Shulman GL. A default mode of brain function. PNAS. 2001; 98(2):676-682. [PubMed: 11209064]

Redcay E, Kennedy DP, Courchesne E. fMRI during natural sleep as a method to study brain function during early childhood. NeuroImage. 2007; 38(4):696-707. [PubMed: 17904385]

Rubinov M, Sporns O. Complex network measures of brain connectivity: uses and interpretations. NeuroImage. 2010; 52(3):1059-1069. [PubMed: 19819337]

Rudie J, Brown J, Beck-Pancer D, Hernandez L, Dennis E, Thompson P, Bookheimer S, Dapretto M. Altered Functional and Structural Brain Network Organization in Autism. NeuroImage: Clinical. 2013; 2:79-94. [PubMed: 24179761]

Rudie JD, Hernandez LM, Brown JA, Colich NL, Beck-Pancer D, Gorrindo P, Thompson PM, Geschwind DH, Bookheimer SY, Levitt P, Dapretto M. Autism-associated Promoter Variant in MET Impacts Structural and Functional Brain Networks. Neuron. 2012a; 75(5):904-915. [PubMed: 22958829]

Rudie JD, Shehzad Z, Hernandez LM, Colich NL, Bookheimer SY, Iacoboni M, Dapretto M. Reduced Functional Integration and Segregation of Distributed Neural Systems Underlying Social and Emotional Information Processing in Autism Spectrum Disorders. Cerebral Cortex. 2012b; 22(5): 1025-1037. [PubMed: 21784971]

Schmithorst VJ, Holland SK. Sex differences in the development of neuroanatomical functional connectivity underlying intelligence found using Bayesian connectivity analysis. NeuroImage. 2007; 35(1):406-419. [PubMed: 17223578] 
Schmithorst VJ, Yuan W. White matter development during adolescence as shown by diffusion MRI. Brain and Cognition. 2010; 72(1):16-25. [PubMed: 19628324]

Schneider JFL, Il-Yasov KA, Hennig J, Martin E. Fast quantitative diffusion-tensor imaging of cerebral white matter form the neonatal period to adolescence. Neuroradiology. 2004; 46:258266. [PubMed: 14999435]

Scott-Van Zeeland A, Abrahams B, Alvarez-Retuerto A, Sonnenblick L, Rudie J, Ghahremani D, Mumford JA, Poldrack RA, Dapretto M, Geschwind DH, Bookheimer SY. Altered Functional Connectivity in Frontal Lobe Circuits Is Associated with Variation in the Autism Risk Gene CNTNAP2. Science Translational Medicine. 2010; 2:1-6.

Seeley WW, Menon V, Schatzberg AF, Keller J, Glover GH, Kenna H, Reiss AL, Greicius MD. Dissociable Intrinsic Connectivity Networks for Salience Processing and Executive Control. Journal of Neuroscience. 2007; 27(9):2349-2356. [PubMed: 17329432]

Sexton CE, Mackay CE, Ebmeier KP. A Systematic Review of Diffusion Tensor Imaging Studies in Affective Disorders. Biological Psychiatry. 2009; 66(9):814-823. [PubMed: 19615671]

Seyffert M, Silva R. FMRI in Pediatric Neurodevelopmental Disorders. Current Pediatric Reviews. $2005 ; 1: 17-24$.

Shaw P, Kabani NJ, Lerch JP, Eckstrand K, Lenroot R, Gogtay N, Greenstein D, Clasen L, Evans A, Rapoport JL, Giedd JN, Wise SP. Neurodevelopmental Trajectories of the Human Cerebral Cortex. Journal of Neuroscience. 2008; 28(14):3586-3594. [PubMed: 18385317]

Shaywitz BA, Shaywitz SE, Pugh KR, Constable RT, Skudlarski P, Fulbright RK, Bronen RA, Fletcher JM, Shankweiler DP, Katz L, Gore JC. Sex differences in the functional organization of the brain for language. Nature. 1995; 373:607-609. [PubMed: 7854416]

Shukla DK, Keehn B, Müller RA. Tract-specific analyses of diffusion tensor imaging show widespread white matter compromise in autism spectrum disorder. Journal of Child Psychology and Psychiatry. 2010; 52(3):286-295. [PubMed: 21073464]

Silk TJ, Vance A, Rinehart N, Bradshaw JL, Cunnington R. White-matter abnormalities in attention deficit hyperactivity disorder: A diffusion tensor imaging study. Human Brain Mapping. 2009; 30(9):2757-2765. [PubMed: 19107752]

Silver M, Janousova E, Hua X, Thompson PM, Montana G. the Alzheimer's Disease Neuroimaging Initiative. Identi cation of gene pathways implicated in Alzheimer's disease using longitudinal imaging phenotypes with sparse regression. NeuroImage. 2012; 63(3):1681-94. [PubMed: 22982105]

Simon TJ, Ding L, Bish JP, McDonald-McGinn DM, Zackai EH, Gee J. Volumetric, connective, and morphologic changes in the brains of children with chromosome 22q11.2 deletion syndrome: an integrative study. NeuroImage. 2005; 25(1):169-180. [PubMed: 15734353]

Simon TJ, Wu Z, Avants B, Zhang H, Gee JC, Stebbins GT. Atypical cortical connectivity and visuospatial cognitive impairments are related in children with chromosome 22q11.2 deletion syndrome. Behavioral and Brain Functions. 2008; 4(25)

Sowell ER, Peterson BS, Thompson PM, Kan E, Yoshii J, Toga AW. Sex Differences in Cortical Thickness Mapped in 176 Healthy Individuals between 7 and 87 years. Cerebral Cortex. 2006; 17 (7):1550-1560. [PubMed: 16945978]

Sowell ER, Peterson BS, Thompson PM, Welcome SE, Henkenius AL, Toga AW. Mapping cortical change across the human life span. Nature Neuroscience. 2003; 6(3):309-315.

Sowell ER, Thompson PM, Holmes CJ, Batth R, Jernigan TL, Toga AW. Localizing Age-Related Changes in Brain Structure between Childhood and Adolescence Using Statistical Parametric Mapping. NeuroImage. 1999; 9:587-597. [PubMed: 10334902]

Sowell ER, Thompson PM, Welcome SE, Henkenius AL, Toga AW, Peterson BS. Cortical Abnormalities in Children and Adolescents with Attention-Deficit Hyperactivity Disorder. The Lancet. 2003; 22:362(9397):1699-1707. December 2003.

Sowell ER, Trauner DA, Gamst A, Jernigan TL. Development of cortical and subcortical brain structures in childhood and adolescence: a structural MRI study. Developmental Medicine and Child Neurology. 2002; 44:4-16. [PubMed: 11811649]

Sporns O, Chialvo DR, Kaiser M, Hilgetag CC. Organization, development and function of complex brain networks. Trends in Cognitive Sciences. 2004; 8(9):418-425. [PubMed: 15350243] 
Stein JL, Medland SE, Vasquez AA, et al. Identification of common variants associated with hippocampal and intracranial volumes. Nature Genetics. 2011; 44(5):552-561. [PubMed: 22504417]

Stejskal EO, Tanner JE. Spin diffusion measurements: Spin-echoes in the presence of a timedependent field gradient. Journal of Chemical Physics. 1965; 42:288-292.

Stevens MC, Pearlson GD, Calhoun VD. Changes in the interaction of resting-state neural networks from adolescence to adulthood. Human Brain Mapping. 2009; 30(8):2356-2366. [PubMed: 19172655]

Sundram F, Campbell LE, Azuma R, Daly E, Bloemen OJN, Barker GJ, Chitnis X, Jones DK, van Ameslvoort T, Murphy KC, Murphy DGM. White matter microstructure in 22q11 deletion syndrome: a pilot diffusion tensor imaging and voxel-based morphometry study of children and adolescents. Journal of Neurodevelopmental Disorders. 2010; 2(2):77-92. [PubMed: 22127856]

Supekar K, Musen M, Menon V. Development of Large-Scale Functional Brain Networks in Children. PLOS Biology. 2009; 7(7):1-15.

Supekar K, Uddin LQ, Prater K, Amin H, Greicius MD, Menon V. Development of functional and structural connectivity within the default mode network in young children. NeuroImage. 2010; 52(1):290-301. [PubMed: 20385244]

Szatmari P, Paterson A, Zwaigenbaum L, et al. Mapping autism risk loci using genetic linkage and chromosomal rearrangements. Nature genetics. 2007; 39:319-328. [PubMed: 17322880]

Taki Y, Thyreau B, Hashizume H, Sassa Y, Takeuchi H, Wu K, Kotozaki Y, Nouchi R, Asano K, Fukuda H, Kawashima R. Linear and curvilinear correlations of brain white matter volume, fractional anisotropy, and mean diffusivity with age using voxel-based and region-of-interest analyses in 246 healthy children. Human Brain Mapping. 2012 Mar 22. [Epub ahead of print].

Tian L, Jiang T, Wang Y, Zang Y, He Y, Liang M, Sui M, Cao Q, Hu S, Peng M, Zhuo Y. Altered resting-state functional connectivity patterns of anterior cingulate cortex in adolescents with attention deficit hyperactivity disorder. Neuroscience Letters. 2006; 400(1-2):39-43. [PubMed: 16510242]

Thomason ME, Chang CE, Glover GH, Gabrieli JDE, Greicius MD, Gotlib IH. Default-mode function and task-induced deactivation have overlapping brain substrates in children. NeuroImage. 2008; 41(4):1493-1503. [PubMed: 18482851]

Thomason ME, Dennis EL, Joshi AA, Joshi SH, Dinov ID, Chang C, Henry ML, Johnson RF, Thompson PM, Toga AW, Glover GH, Van Horn JD, Gotlib IH. Resting-state fMRI can reliably map neural networks in children. NeuroImage. 2011; 55(1):165-175. [PubMed: 21134471]

Thomason ME, Thompson PM. Diffusion Imaging, White Matter and Psychopathology. Annual Review of Clinical Psychology. 2011 Apr.7:63-85.

Thomason ME, Yoo DJ, Glover GH, Gotlib IH. BDNF Genotype Modulates Resting Functional Connectivity in Children. Front Hum Neurosci. 2009; 3(55):1-10. [PubMed: 19255629]

Thompson PM, Bartzokis G, Hayashi KM, Klunder AD, Lu PH, Edwards N, Hong MS, Yu M, Geaga JA, Toga AW, Charles C, Perkins DO, McEvoy J, Hamer RM, Tohen M, Tollefson GD, Lieberman JA. for the HGDH Study Group . Time-Lapse Mapping Reveals Different Disease Trajectories in Schizophrenia depending on Antipsychotic Treatment. Cerebral Cortex. 2009; 19:1107-1123. [PubMed: 18842668]

Thompson PM, Giedd JN, Woods RP, MacDonald D, Evans A, Toga A. Growth patterns in the developing brain detected by using continuum mechanical tensor maps. Nature Letters. 2000; 404:1-4.

Thompson PM, Glahn D, Ge T, Nichols TE. Genetics of the Connectome, Invited Review Paper for the Special Issue on the Connectome. NeuroImage. 2013 submitted, March 2013.

Thompson PM, Jahanshad N. Ironing out neurodegeneration: Is iron intake important during the teenage years? Expert Review of Neurotherapeutics. 2012 Jun.

Thompson PM, Lee AD, Dutton RA, Geaga JA, Hayashi KM, Eckert MA, Bellugi U, Galaburda AM, Korenberg JR, Mills DL, Toga AW, Reiss AL. Abnormal Cortical Complexity and Thickness Profiles Mapped in Williams Syndrome. Journal of Neuroscience. 2005 Apr 20; 25(18):41464158. [PubMed: 15843618] 
Thompson PM, Martin NG, Wright MJ. Imaging Genomics. Invited Review paper for: Current Opinion in Neurology. 2010 Aug; 23(4):368-73.

Thompson, PM.; Narr, KL.; Blanton, RE.; Toga, AW. Mapping structural alterations of the corpus callosum during brain development and degeneration. In: Iacoboni, M.; Zaidel, E., editors. The Corpus Callosum. Klüwer; Boston, MA: 1999.

Thompson PM, Vidal CN, Giedd JN, Gochman P, Blumenthal J, Nicolson R, Toga AW, Rapoport JL. Mapping Adolescent Brain Change Reveals Dynamic Wave of Accelerated Gray Matter Loss in Very Early--Onset Schizophrenia. Proceedings of the National Academy of Sciences of the USA. 2001 Sep 25; 98(20):11650-11655. [PubMed: 11573002]

Toga, AW.; Thompson, PM. Measuring, Mapping, and Modeling Brain Structure and Function. SPIE Medical Imaging Symposium; Feb. 1997; Newport Beach, CA, USA. 1997. SPIE Lecture Notes

Toga AW, Thompson PM. Mapping brain asymmetry. Nature Neuroscience. 2003; 4:37-48.

Toga AW, Thompson PM. Connectomics Sheds New Light on Alzheimer's Disease. Biological Psychiatry. 2013; 73(5):390-2. [PubMed: 23399468]

Tournier JD, Calamante F, Gadian DG, Connelly A. Direct estimation of the fiber orientation density function from diffusion-weighted MRI data using spherical deconvolution. NeuroImage. 2004; 23(3):1176-1185. [PubMed: 15528117]

Tuch DS, Reese TG, Wiegell MR, Makris N, Belliveau JW, Wedeen VJ. High angular resolution diffusion imaging reveals intravoxel white matter fiber heterogeneity. Magn Res Med. 2002; 48:577-582.

Turkheimer E, Farace E. A reanalysis of gender differences in IQ scores following unilateral brain lesions. Psychological Assessment. 1992; 4(4):498-501.

Uddin LQ, Supekar K, Menon V. Typical and atypical development of functional human brain networks: insights from resting-state FMRI. Frontiers in Systems Neuroscience. 2010; 4:21. [PubMed: 20577585]

Vidal CN, Hayashi KM, Geaga JA, Sui Y, McLemore LE, Alaghband Y, Giedd JN, Gochman P, Blumenthal J, Gogtay N, Nicolson R, Toga AW, Rapoport JL, Thompson PM. Dynamically Spreading Frontal and Cingulate Deficits Mapped in Adolescents with Schizophrenia. Archives of General Psychiatry. 2006 Jan; 63(1):25-34. [PubMed: 16389194]

Villalon J, Jahanshad N, Beaton E, Toga AW, Thompson PM, Simon TJ. White matter microstructural abnormalities in children with chromosome 22q11.2 deletion syndrome, Fragile X or Turner syndrome as evidenced by diffusion tensor imaging. NeuroImage. 2013 submitted.

Wåhlstedt C, Thorell LB, Bohlin G. Heterogeneity in ADHD: Neuropsychological pathways, comorbidity, and symptom domains. Journal of Abnormal Child Psychology. 2009; 37(4):551564. [PubMed: 19016322]

Walter E, Mazaika PK, Reiss AL. Insights into brain development from neurogenetic syndromes: evidence from Fragile X syndrome, Williams syndrome, Turner syndrome and Velocardiofacial syndrome. Neuroscience. 2009; 164:257-271. [PubMed: 19376197]

Wang L, Zhu C, He Y, Zang Y, Cao Q, Zhang H, Zhong Q, Wang Y. Altered small-world brain functional networks in children with attention-deficit/hyperactivity disorder. Human Brain Mapping. 2009; 30(2):638-649. [PubMed: 18219621]

Wang L, Zhu C, He Y, Zhong Q, Zang Y. Gender effect on functional networks in resting brain. Medical Imaging and Informatics. 2008; 4987:160-168.

Weng SJ, Wiggins JL, Peltier SJ, Carrasco M, Risi S, Lord C, Monk CS. Alterations of resting state functional connectivity in the default network in adolescents with autism spectrum disorders 2 . Brain Research. 2010; 1313:202-214. [PubMed: 20004180]

Winterer G, Konrad A, Vucurevic G, Musso F, Stoeter P, Dahmen N. Association of the 5' end neuregulin-1 (NRG1) gene variation with subcortical medial frontal microstructure in humans. NeuroImage. 2008; 40:712-718. [PubMed: 18255317]

Yamagata B, Barnea-Goraly N, Marzelli MJ, Park Y, Hong DS, Mimura M, Reiss AL. White Matter Aberrations in Prepubertal Estrogen-Naive Girls with Monosomic Turner Syndrome. Cerebral Cortex. 2012; 22(12):2761-2768. [PubMed: 22172580] 
Yu-Feng Z, Yong H, Chao-Zhe Z, Qing-Jiu C, Man-Qiu S, Meng L, Li-Xia T, Tian-Zi J, Yu-Feng W. Altered baseline brain activity in children with ADHD revealed by resting-state functional MRI. Brain and Development. 2007; 29:83-91. [PubMed: 16919409]

Zhai G, Lin W, Wilber KP, Gerig G, Gilmore JH. Comparisons of Regional White Matter Diffusion in Healthy Neonates and Adults Performed with a 3.0-T Head-only MR Imaging Unit. Radiology. 2003; 229(3):673-681. [PubMed: 14657305]

Zhan, L.; Chiang, MC.; Barysheva, M.; Toga, AW.; McMahon, KL.; de Zubicaray, GI.; Meredith, M.; Wright, MJ.; Thompson, PM. How Many Gradients are Sufficient in High-Angular Resolution Diffusion Imaging (HARDI)?. Workshop on Diffusion Tensor Imaging, Medical Image Computing and Computer Assisted Intervention (MICCAI); New York. September 10 (2008); 2008.

Zhan, L.; Franc, D.; Patel, V.; Jahanshad, N.; Yan Jin Mueller, BA.; Bernstein, MA.; Borowski, BJ.; Jack, CR., Jr; Toga, AW.; Lim, KO.; Thompson, PM. How do Spatial and angular resolution affect brain connectivity maps from Diffusion MRI?. Proc. 9th IEEE ISBI; Barcelona. 2012a. (to appear)

Zhan L, Leow AD, Aganj I, Lenglet C, Sapiro G, Yacoub E, Harel N, Toga AW, Thompson PM. Differential Information Content in Staggered Multiple Shell HARDI Measured by the Tensor Distribution Function. ISBI. 2011

Zhan, L.; Leow, AD.; Barysheva, M.; Feng, A.; Toga, AW.; Sapiro, G.; Harel, N.; Lim, KO.; Lenglet, C.; McMahon, KL.; de Zubicaray, GI.; Wright, MJ.; Thompson, PM. In: Pohl, Kilian; Joshi, Sarang; Wells, Sandy, editors. Investigating the uncertainty in multi-fiber estimation in High Angular Resolution Diffusion Imaging. Workshop on Probabilistic Modeling in Medical Image Analysis (PMMIA); Medical Image Computing and Computer Assisted Intervention (MICCAI); London. September 20 (2009); 2009a.

Zhan L, Leow AD, Chiang MC, Barysheva M, Lee AD, Toga AW, McMahon KL, de Zubicaray GI, Wright MJ, Thompson PM. How does Angular Resolution Affect Diffusion Imaging Measures? NeuroImage. 2009b Oct 9. 2009. [Epub ahead of print].

Zhan L, Jahanshad N, Ennis DB, Bernstein MA, Borowski BJ, Jack CR Jr, Toga AW, Leow AD, Thompson PM. Angular versus spatial resolution trade-offs for diffusion imaging under time constraints. Human Brain Mapping. 2012b Apr 25.

Zielinski BA, Gennatas ED, Zhou J, Seeley WW. Network-level structural covariance in the developing brain. Proceedings of the National Academy of Sciences. 2010; 107(42):1819118196. 


\section{Highlights}

- We review recent work over the last 13 years in brain structural and functional connectivity

- We review research in typical development and neurodevelopmental disorders

- We expect that this review will help future researchers in the field of connectomics 


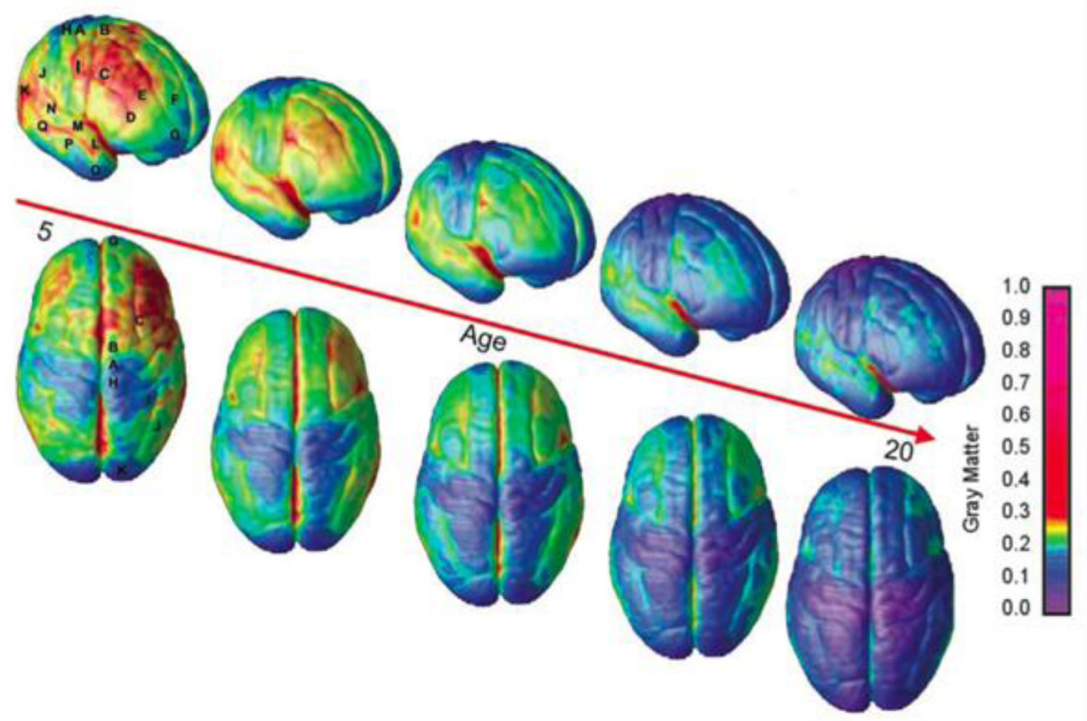

Figure 1. Decreases in regional gray matter volume, in normal children, between age 5 and age 20

As a general principle of development, cortical regions that are concerned with more lowlevel, primary functions - such as vision and sensation - mature more quickly than the regions subserving higher order cognition. Here the loss of gray matter volume is thought to be due to greater myelination of the cortex, rather than solely due to synaptic and dendritic pruning. Vascular and glial changes many also play a role. Reprinted with permission from Gogtay et al., PNAS 2004. 


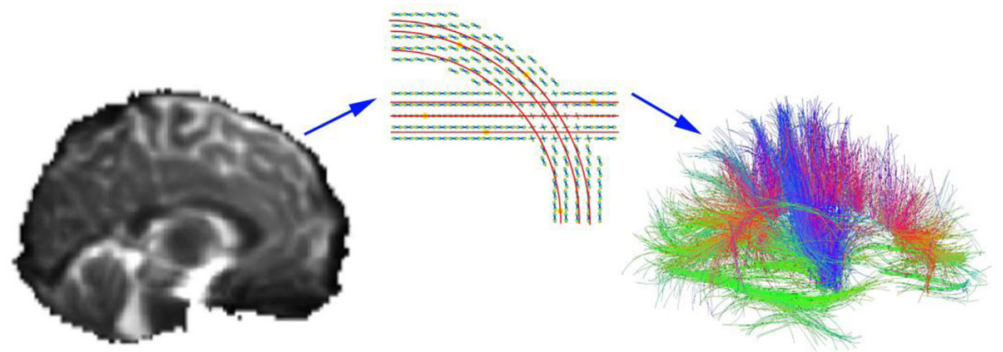

Figure 2. Diffusion tensor imaging and tractography

In whole brain tractography, a set of diffusion weighted images (left) are collected to show how rapidly water is diffusing in a range of difference directions. By sample a large number of directions, a diffusion function (little crosses in the middle panel) can be reconstructed the peaks in this function tend to point along axons and major tracts. Tract tracing algorithms can sew together the paths of maximal diffusion into curves and fiber bundles. The right panel shows the set of recovered fibers - red, green, and blue colors show the directions of the fibers. These can be grouped into meaningful anatomical bundles and their integrity and connectivity can be assessed. The middle image is taken from Aganj et al., 2011. 


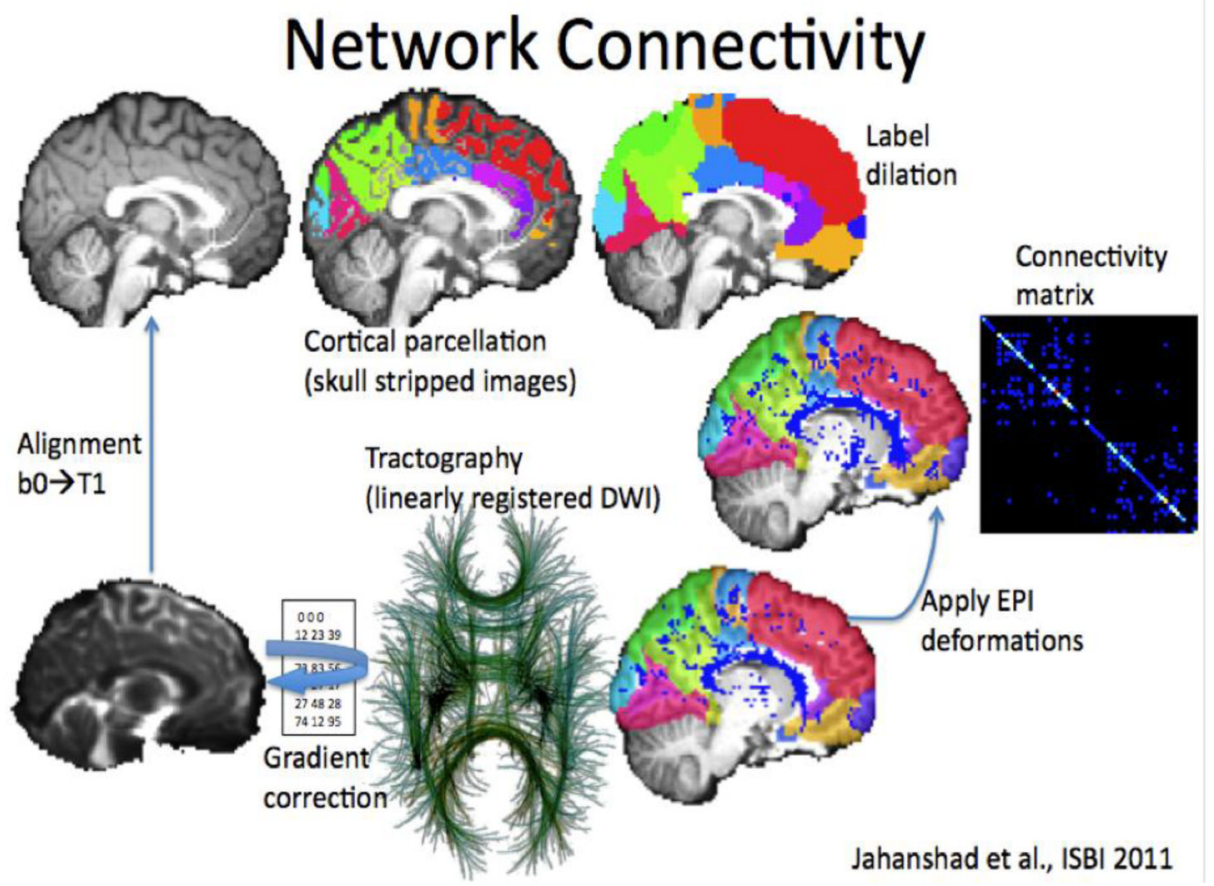

Figure 3. Methods for graph theoretical analyses of structural connectivity, computed from diffusion imaging data

To compute connectivity maps, a set of cortical regions is defined on a standard anatomical MRI scan. The tracing of fiber tracts in diffusion images can be used to create a vast set of fiber connections in the brain. These are then assigned to different regions of interest. The matrix on the far right can be used to count how many of the fibers pass through any pair of regions; it can also stored information on their integrity or other biological parameters. Reprinted with permission from Jahanshad et al., 2011. 


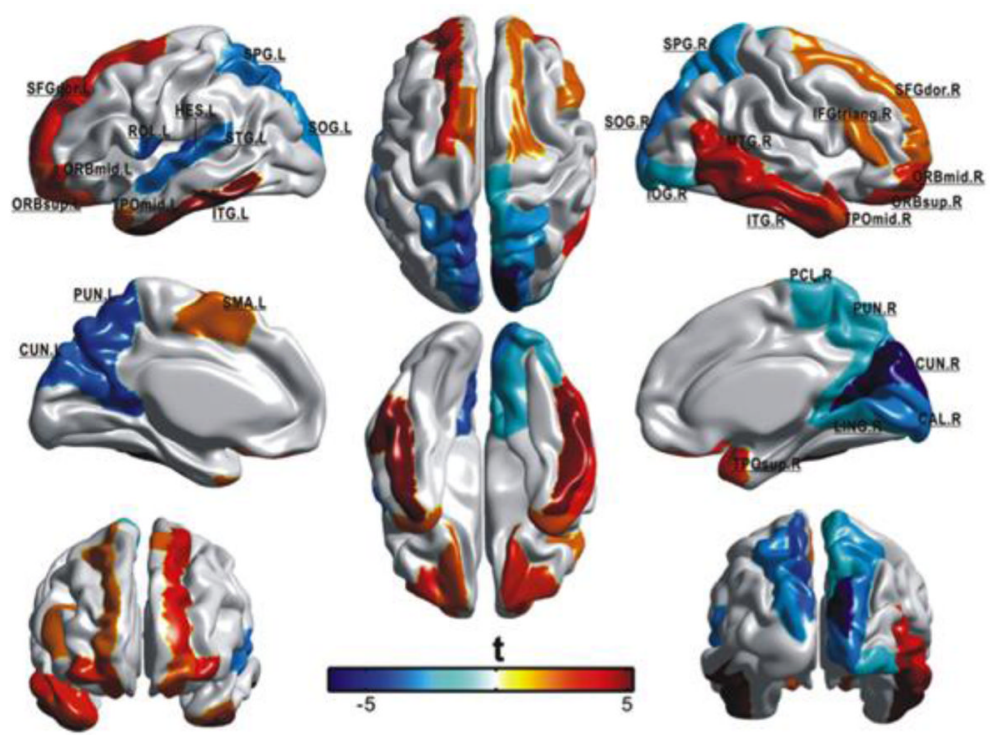

Figure 4. Regions that show age-related effects in regional efficiency in 95 subjects 19-85 years old

Red indicates increases in efficiency with age, blue indicate decreases in efficiency with age. Reprinted with permission from Gong et al., 2009. See Gong et al., 2009 supplemental material for abbreviations of cortical regions. 


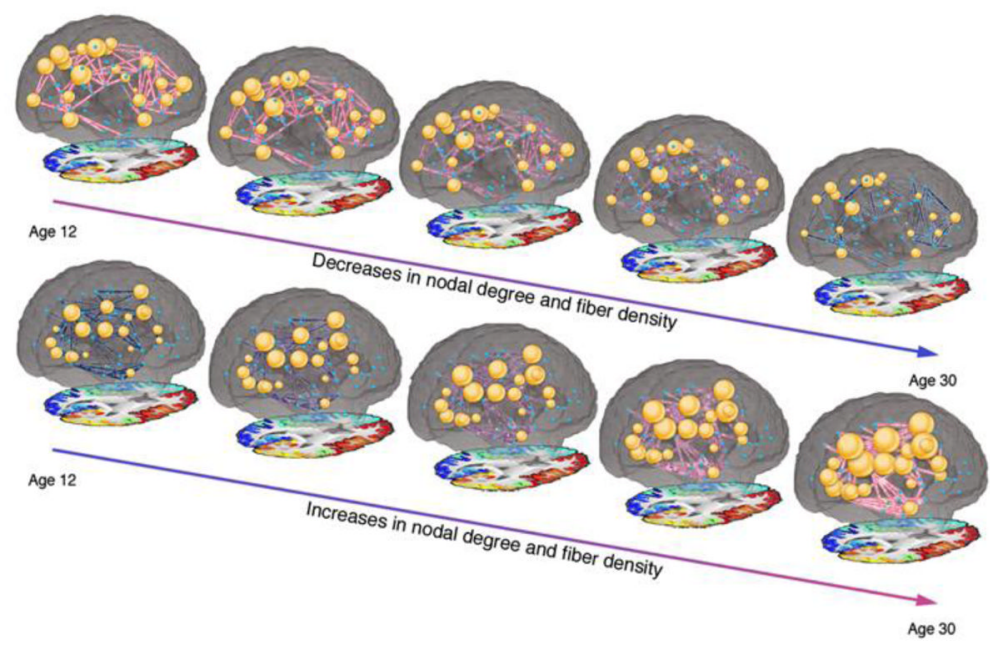

Figure 5. Age-related increases and decreases in nodal degree and edge fiber density in 439 subjects aged 12-30

This study is based on HARDI, a form of diffusion imaging that can be used to recover anatomical connections. Colors correspond to the fiber density, with red indicating greater values and blue indicating smaller values. The diameter of nodes corresponds to their degree. Reprinted with permission from Dennis et al., 2013. 


\section{Fiber Density}

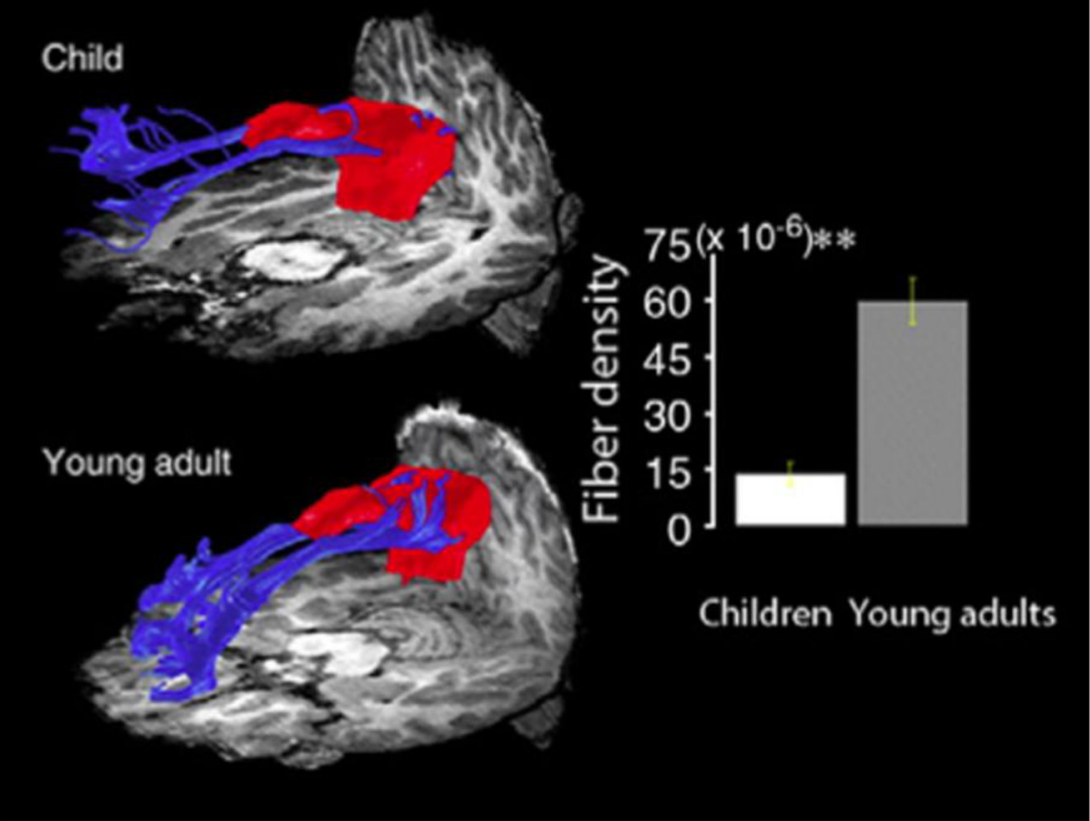

Figure 6. Maturation of the connection between the PCC (posterior cingulate cortex) and mPFC (medial prefrontal cortex), two main hubs of the DMN (default mode network) between 18 7-9 year olds and 15 19-22 year olds

DTI tractography depicting developmental effects in fibers between PCC and mPFC. Bar graph showing significant difference in fiber density $(p \ll 0.0001$, indicated by $* *)$.

Reprinted with permission from Supekar et al., NeuroImage 2010. 


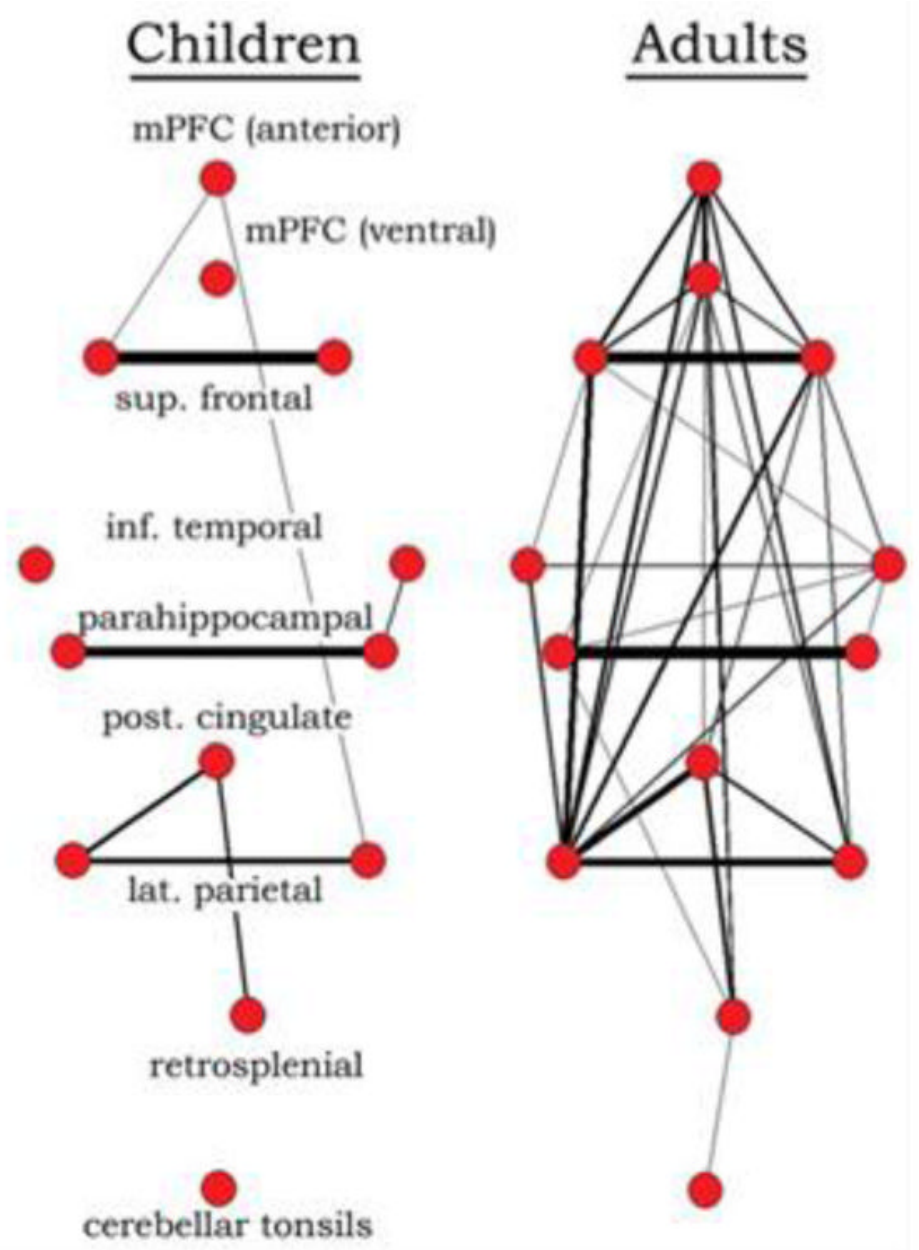

Figure 7. Differences in the connectivity of the DMN between children (7-9 y) and adults (21-31 у)

Graph visualization of DMN regions in children and adults generated by correlating the time series' of 13 regions, including hubs of the DMN. In children (7-9 years old), DMN regions are sparsely connected, while they appear highly integrated in adults (21-31 years old). Reprinted with permission from Fair et al., 2008. 


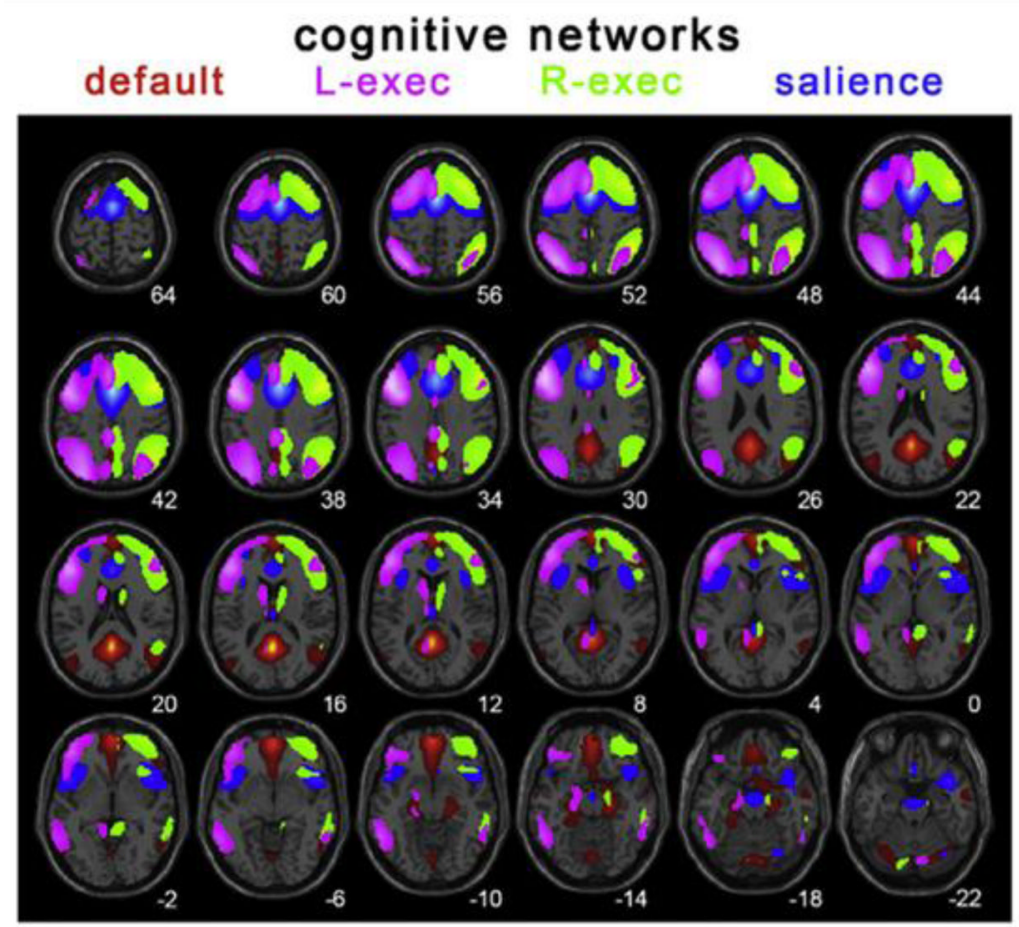

Figure 8. Spatial renderings of components corresponding to the default (red), left executive (pink), right executive (green) and salience networks (blue) generated from group ICA analysis of 65 children aged 9-15 years

Reprinted with permission from Thomason et al., 2011. 


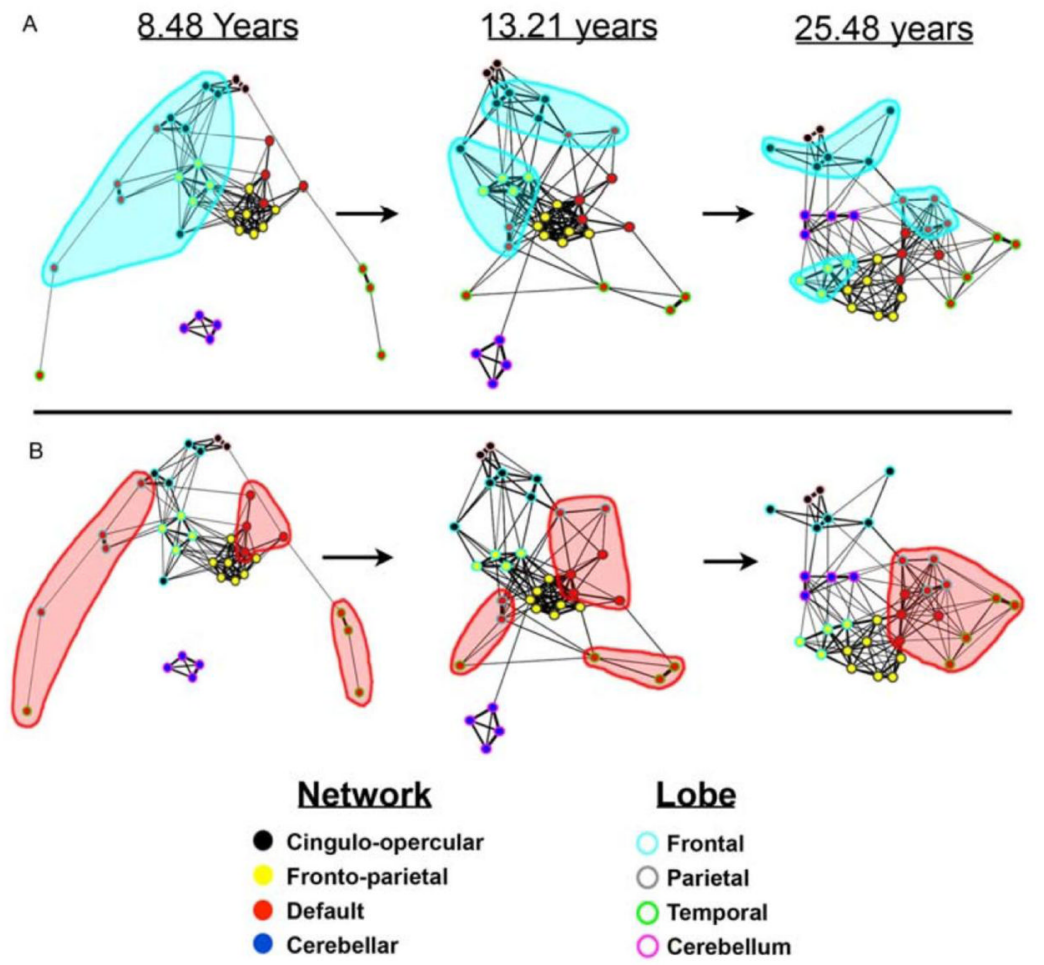

Figure 9. Maturation from "local" organization to "distributed" organization, as measured by functional graph theoretical measures

Frontal regions are highlighted in blue in A, notice they are closely connected in children and less so in adults. The DMN, a collection of anatomically distributed regions, are highlighted in red in B. Notice they are segregated in children and highly integrated in adults. Reprinted with permission from Fair et al., 2009. 


\section{Table 1}

List of studies of development of structural and/or functional connectivity in typically developing subjects covered in this review.

\begin{tabular}{|c|c|c|c|}
\hline Authors & Ages studied & Func(tional) or Struct(ural) & Analyses \\
\hline Morriss et al., 1999 & 30 subjects, 1 day- $17 \mathrm{y}$ & Struct & DTI \\
\hline Mukherjee et al., 2001 & 153 subjects, 1 day- 11 y & Struct & DTI \\
\hline Zhai et al., 2003 & 20 neonates, 8 adults (mean age $28 \mathrm{y}$ ) & Struct & DTI \\
\hline Gilmore et al., 2004 & 20 neonates & Struct & DTI \\
\hline Ben Bashat et al., 2005 & 36 subjects, 4 mo- 23 y & Struct & DTI, DWI \\
\hline Barnea-Goraly et al., 2005 & 30 subjects, $6-19$ y & Struct & DTI \\
\hline Schneider et al., 2004 & 52 subjects, 1 day- $16 \mathrm{y}$ & Struct & $\begin{array}{l}\text { DTI (high angular } \\
\text { resolution) }\end{array}$ \\
\hline McLaughlin et al.. 2007 & $\begin{array}{l}10 \text { subjects, } 7-12 \text { y; } 36 \text { sub } 13-18 \text { y, } 25 \text { sub } 25- \\
40 \text { y, } 11 \text { sub } 60-80 \text { y }\end{array}$ & Struct & DTI \\
\hline Hasan et al., 2009 & 36 subjects, $6-19$ y; 63 subjects, $20-59$ y & Struct & DTI, tractography \\
\hline Giorgio et al., 2008 & 42 subjects, $13-21 ; 20$ subjects $23-42$ & Struct & $\begin{array}{l}\text { DTI (high angular } \\
\text { resolution) }\end{array}$ \\
\hline Gao et al., 2009a & 60 subjects, 3 weeks- 2 y & Struct & DTI \\
\hline Kochunov et al., 2010 & 831 subjects, $11-90$ y & Struct & DTI \\
\hline Asato et al., 2010 & 114 subjects, $8-28$ y & Struct & DTI \\
\hline Chiang et al., 2011 & 705 subjects, $12-29$ y & Struct & DTI \\
\hline Supekar et al., 2010 & $\begin{array}{l}\text { In total: } 23 \text { sub } 7-9 \text { y, } 22 \text { sub } 19-22 \text { y, for DTI: } \\
18 \text { sub } 7-9 \text { y, } 15 \text { sub } 19-22 \text { y }\end{array}$ & Struct and Func & DTI, tractography, ICA \\
\hline Taki et al., 2012 & 246 subjects $5-19$ y & Struct & DTI \\
\hline Jahanshad et al., 2012 & 615 subjects $20-30$ y & Struct & DTI \\
\hline Gong et al., 2009 & 95 subjects $19-85$ y & Struct & graph theory \\
\hline Hagmann et al., 2010 & 30 subjects 18 mo- 18 y & Struct & graph theory \\
\hline Fan et al., 2011 & 28 subjects 1 mo- 2 y (longitudinal) & Struct & graph theory \\
\hline Dennis et al., 2013 & 439 subjects $12-30$ y & Struct & graph theory \\
\hline Redcay et al., 2007 & 13 subjects $30-50 \mathrm{mo}$ & Func & seed-based \\
\hline Lin et al., 2008 & $38 \operatorname{sub} 2-4 \mathrm{w}, 261 \mathrm{y}, 212 \mathrm{y}$ & Func & seed-based \\
\hline Fair et al., 2008 & 66 sub 7-9 y, $5310-15$ y, $9119-31$ y & Func & seed-based \\
\hline Kelly et al., 2009 & $14 \operatorname{sub} 8-13,1213-17,1419-24$ & Func & seed-based \\
\hline Dosenbach et al., 2010 & 61 sub 7-11 y, 61 24-30 y & Func & seed-based \\
\hline Fransson et al., 2007 & 12 premature $24-27$ w GA & Func & ICA \\
\hline Liu et al., 2008 & 11 sub $11-14$ mo & Func & ICA \\
\hline Thomason et al., 2008 & 16 sub $9-12$ y & Func & ICA \\
\hline Gao et al., $2009 \mathrm{~b}$ & $\begin{array}{l}20 \text { neonates, } 241 \text { y, } 272 \text { y, } 15 \text { adults (mean age } \\
30 \text { ) }\end{array}$ & Func & ICA, graph theory \\
\hline Stevens et al., 2009 & 100 sub $12-30$ y & Func & ICA, Granger causality \\
\hline Thomason et al., 2011 & 65 sub 9-15 y (longitudinal) & Func & seed-based/ICA \\
\hline Fair et al., 2007 & 49 sub $7-9$ y, 43 10-15 y, $4721-31$ y & $\overline{\text { Func }}$ & graph theory \\
\hline
\end{tabular}




\begin{tabular}{|llll|}
\hline Authors & Ages studied & Func(tional) or Struct(ural) & Analyses \\
\hline Supekar et al., 2009 & 23 sub 7-9 y, 22 19-22 y & Func & graph theory \\
\hline Fair et al., 2009 & 66 sub 7-9 y, 53 10-15 y, 91 19-31 y & Func & graph theory \\
\hline
\end{tabular}

Y indicates years, mo indicates months when referring to age of subjects. $G A=$ gestational age, func=functional, struct=structural. 
Table 2

List of studies of development of structural and/or functional connectivity in subjects with a developmental disorder covered in this review.

\begin{tabular}{|c|c|c|c|}
\hline Authors & Disorder & Func or Struct & Analyses \\
\hline Barnea-Goraly et al., 2004 & Autism & Struct & DTI \\
\hline Ben Bashat et al., 2007 & Autism & Struct & DTI (high b value) \\
\hline Barnea-Goraly et al., 2010 & Autism & Struct & DTI \\
\hline Shukla et al., 2010 & Autism & Struct & DTI \\
\hline Barnea-Goraly et al., 2003 & Fragile $X$ & Struct & DTI \\
\hline Haas et al., 2009 & Fragile $X$ & Struct & DTI, tractography \\
\hline Simon et al., 2005 & $22 q \mathrm{DS}$ & Struct & DTI \\
\hline Simon et al., 2008 & $22 q \mathrm{DS}$ & Struct & DTI \\
\hline Sundram et al., 2010 & $22 q \mathrm{DS}$ & Struct & DTI \\
\hline Villalon et al., 2013 & $22 q \mathrm{DS}$ & Struct & DTI, tractography \\
\hline Hoeft et al., 2007 & Williams & Struct & DTI, tractography \\
\hline Arlinghaus et al., 2011 & Williams & Struct & DTI \\
\hline Haas et al., 2011 & Williams & Struct & DTI, tractography \\
\hline Jabbi et al., 2012 & Williams & Struct & DTI, tractography \\
\hline Molko et al., 2004 & Turner & Struct & DTI \\
\hline Holzapfel et al., 2006 & Turner & Struct & DTI \\
\hline Yamagata et al., 2012 & Turner & Struct & DTI, tractography \\
\hline Ashtari et al., 2005 & ADHD & Struct & DTI \\
\hline Hamilton et al., 2008 & ADHD & Struct & DTI \\
\hline Pavuluri et al., 2009 & ADHD & Struct & DTI \\
\hline Silk et al., 2009 & ADHD & Struct & DTI, tractography \\
\hline Li et al., 2011 & ADHD & Struct & DTI \\
\hline Cherkassky et al., 2006 & Autism & Func & seed-based \\
\hline Just et al., 2007 & Autism & Func & seed-based \\
\hline Kennedy et al., 2008 & Autism & Func & seed-based \\
\hline Monk et al., 2009 & Autism & Func & seed-based \\
\hline Noonan et al., 2009 & Autism & Func & seed-based \\
\hline Weng et al., 2010 & Autism & Func & seed-based \\
\hline Rudie et al., $2012 b$ & Autism & Func & seed-based \\
\hline Debbane et al., 2012 & $22 q \mathrm{DS}$ & Func & ICA \\
\hline Kesler et al., 2007 & Turner & Func & unknown \\
\hline Bray et al., 2011 & Turner & Func & seed-based \\
\hline Bray et al., 2012 & Turner & Func & seed-based \\
\hline Cao et al., 2006 & ADHD & Func & voxel-wise seed-based \\
\hline Tian et al., 2006 & ADHD & Func & seed-based \\
\hline Castellanos et al., 2008 & ADHD & Func & seed-based \\
\hline
\end{tabular}




\begin{tabular}{|llll|}
\hline Authors & Disorder & Func or Struct & Analyses \\
\hline Wang et al., 2009 & ADHD & Func & graph theory \\
\hline
\end{tabular}

Func=functional, struct=structural. 